\title{
Impact of Atmospheric Circulation and Meteorological Parameters on Wintertime Atmospheric Extinction in Chengdu and Chongqing of Southwest China during 2001-2016
}

\author{
Guangming Shi ${ }^{1,2}$, Fumo Yang ${ }^{1,2 *}$, Leiming Zhang ${ }^{3}$, Tianliang $\mathrm{Zhao}^{4}$, Jun $\mathrm{Hu}^{4}$ \\ ${ }^{1}$ College of Architecture and Environment, Sichuan University, Chengdu 610065, China \\ ${ }^{2}$ National Engineering Research Center for Flue Gas Desulfurization, Department of Environmental Science and \\ Engineering, Sichuan University, Chengdu 610065, China \\ ${ }^{3}$ Air Quality Research Division, Science and Technology Branch, Environment and Climate Change Canada, Toronto, \\ Canada \\ ${ }^{4}$ Key Laboratory for Aerosol-Cloud-Precipitation of China Meteorological Administration, Nanjing University of \\ Information Science and Technology, Nanjing 210044, China
}

\begin{abstract}
This study investigated the effect of atmospheric circulation and meteorological parameters on the surface atmospheric extinction coefficient (SEC) in Chengdu and Chongqing of southwest China during the winters of 2001-2016. Four predominant circulation types (CT) were first identified, representing a high-pressure system in the north (CT 1), a lowpressure system in the north (CT 2), a weak high-pressure system (CT 3) and a local low-pressure system (CT 4) at a geopotential height of $850 \mathrm{hPa}$. In Chengdu, variation in the SEC between the CTs was dominated by meteorological factors, such as wind, subsidence, inversion and planetary boundary layer height (PBLH), whereas the variation within each CT was mainly controlled by dispersion-related parameters (such as wind speed and PBLH for CTs 1, 2 and 4, which were associated with strong weather systems) or chemistry-related parameters (such as RH and T for CT 3, which was associated with a weak system). In Chongqing, dispersion and chemical processes were equally important due to the weaker impact of the atmospheric circulation. A new method for discriminating between synoptic and non-synoptic signals in SEC time series was proposed to estimate the effect of the circulation intensity by considering multiple influential meteorological parameters. Atmospheric circulation heightened the interannual SEC variations by $23 \%$ in both Chengdu and Chongqing in more than half of the years but reduced them by $44.79 \%$ and $8.02 \%$ in Chengdu and Chongqing, respectively, in the remaining years. Synoptic changes were estimated to contribute $5-10 \%$ of the decreasing SEC trend but less than $1 \%$ of the increasing trend.
\end{abstract}

Keywords: Atmospheric extinction coefficient; Atmospheric circulation; Meteorological parameters.

\section{INTRODUCTION}

The deterioration of air quality in China, mainly caused by high aerosol loading associated with the rapidly increasing energy consumption, industrialization and urbanization, has been a severe environmental issue in the recent decades (Chan and Yao, 2008). Surface atmospheric extinction coefficient (SEC) is widely used as a proxy of particulate pollution (Li et al., 2016). SEC can be inferred from horizontal visibility (VIS) (Che et al., 2007), scattering and absorption coefficient (He et al., 2009), or column integrated aerosol optical depth (AOD) (Lin et al., 2015).

\footnotetext{
* Corresponding author.

E-mail address: fmyang@scu.edu.cn
}

The level of particulate pollution is controlled by emission intensity, secondary aerosol formation, dispersion, transport and removal of pollutants. All these processes are strongly affected by meteorological parameters, including wind speed (WS), wind direction (WD), relative humidity (RH), temperature (T) and planetary boundary layer height (PBLH). Weak wind is unfavorable for the dispersion, transport and dry deposition processes (Zhang et al., 2001; Zhang et al., 2015a; Wang et al., 2016), hence responsible for the accumulation of air pollutants. WD controls the direction of horizontal transport and makes different air quality conditions associated with surrounding regions (He et al., 2009; Zhang et al., 2015a). RH and T are associated with the gas-to-particle conversion process by shifting the partition of semi-volatile species into the aerosol phase (Hu et al., 2008; Zhang et al., 2015b). Low PBLH, generally accompanied with atmospheric inversion and subsidence, 
suppresses vertical mixing and causes high concentration of pollutants (Wu et al., 2013; Petaja et al., 2016). The meteorological parameters affecting air quality are interrelated and modulated by synoptic-scale circulation (Zhang et al., 2012). Under the condition of quasi-stable emission, circulation pattern will be the predominant factor causing day-to-day variations of air pollutants. The impact of atmospheric circulations on air quality has been investigated for pollution episodes in various areas of China. For example, stable and weak anti-cyclone synoptic condition was in favor of heavy air pollution formation (Wei et al., 2011; Liu et al., 2013) and variant circulation patterns controlled the accumulation, spikes and dissipation of pollutants (Chen et al., 2008) in northern China. Similarly, in eastern China pollution episodes were associated with the uniform pressure field and anti-cyclone circulation, while clean episodes occurred when strong southeastward cold air advection prevailed in lower troposphere (Zheng et al., 2015). In southern China, poor air quality was typically associated with the warm period before a cold front and the subsidence period controlled by a tropical cyclone (Feng et al., 2007; Wu et al., 2013; Yan et al., 2016). However, the impact of atmospheric circulation on air quality in southwestern China has rarely been investigated.

In addition to the case studies mentioned above, circulation type classification (CTC) is another wellestablished tool for analyzing the relationships between the circulation patterns and environmental variables (Philipp et al., 2010). Through implementing CTC, the time series of circulation fields, such as pressure and wind, are categorized as several circulation types (CT) based on the similarity between these fields. Accordingly, the time series of environmental variables are grouped into different CTs. One advantage of doing CTC is that certain CT represents typical weather condition (combination of meteorological parameters). Hence, it is quite straightforward to investigate the influence of circulation on air quality by analyzing the difference of environmental variables between different CTs. Zhang et al. (2012) identified nine CTs and analyzed the air quality and pollutant transport pathways for each CT in Beijing in northern China. Zhang et al. (2013) classified seven CTs and found that the cyclone-related CTs were associated with relatively higher $\mathrm{O}_{3}$ concentrations and variations in Hong Kong. Ye et al. (2016) used CTC to examine the impact of circulation patterns on planetary boundary structures and air quality in North China Plain.

The interannual variations and long-term trends of air quality are determined by the variations in both air pollutant emission and atmospheric circulation. One advantage of doing CTC is that it provides a technique to discriminate the circulation related signals from other signals. Comrie (1992) presented a method to decompose environmental data into its synoptic and non-synoptic components using occurrence frequencies of CTs. Hegarty et al. (2007) further considered both the intensity and frequency of each CT and demonstrated that synoptic signal contributed $46 \%$ of the interannual variability in summertime $\mathrm{O}_{3}$ in the northeastern United States. Zhang et al. (2012) found that $54 \%$ of the visibility improvements were attributed to the
CT frequency anomaly during the 2008 Olympics in Beijing. Zhang et al. (2013) presented that $36 \%$ of the observed decadal increasing trends of $\mathrm{O}_{3}$ in Hong Kong were results of the interannual variability in frequencies and intensities of circulation patterns.

Theoretically, it is reasonable to consider synchronously intensities and frequencies of CTs while discriminating between interannual synoptic and non-synoptic signals. (Hegarty et al., 2007). For each CT, the anomalies of environmental variables $(\Delta \mathrm{X}$, defined as the difference between the environmental variables for a given year and multi-year average within the study period) were linearly correlated to certain predefined circulation intensity index (CII). Hence, for each year $\Delta \mathrm{X}$ could be derived from CII and added to the synoptic signals from CT frequency only (Hegarty et al., 2007). However, several issues still need to be addressed in these procedures. Firstly, $\Delta \mathrm{X}$ contains information about non-synoptic factors. Specifically, in China the dramatic interannual variations of anthropogenic emissions should contribute to $\Delta \mathrm{X}$ significantly. Secondly, single CII seems not to be fully representative of the intensity of CT. For instance, Zhang et al. (2013) provided four possible indexes, including the domain-averaged sea level pressure, the central pressure of a dominant system, the pressure gradient, and the effective intensity, and eventually selected the pressure gradient and effective intensity as CII for high- and low-pressure system, respectively, based on the best correlation with $\mathrm{O}_{3}$ anomalies. Apparently, the contribution of indexes with weaker correlation was ignored, suggesting the need of improving this method.

Chengdu and Chongqing are the two biggest cities in Sichuan Basin (southwestern China) and acknowledged as one of the most polluted regions in China (Wu et al., 2012; Wang et al., 2014; Meng et al., 2015; Zhao et al., 2016b; Tao et al., 2017). As shown in Fig. 1, the altitude is lower than $500 \mathrm{~m}$ in the basin areas and exceeds $1000 \mathrm{~m}$ at the basin edges. The annual average visibilities of these cities have been less than $10 \mathrm{~km}$ since the 1970s (Chen and Xie, 2012) and aerosol pollution events occurred mainly in winter (Wang et al., 2014; Che et al., 2015; Zhao et al., 2016b; Wang et al., 2017). Since the West Development Project launched in 2000 by the Chinese government, energy consumption and corresponding pollutant emission have increased dramatically. Meanwhile, stringent air pollution control measures have been taken, such as removal of "yellow label" vehicles and migration of industries away from urban areas (Wang et al., 2017). These factors, accompanied with the effects of climate change and urbanization (Miao et al., 2015; Zhao et al., 2016a), complicated recent air quality trends in Chengdu and Chongqing. For example, satellite-observed AOD reached the maximum value in 2010 and then started decreasing in the past decade in this region (Liu et al., 2016). Similarly, atmospheric extinction shifted from increasing trend to decreasing one around 2006 in southwestern China (Li et $a l ., 2016)$. The goals of this study are to (1) identify the main atmospheric circulation patterns influencing Sichuan Basin in winter; (2) investigate the relationships between 


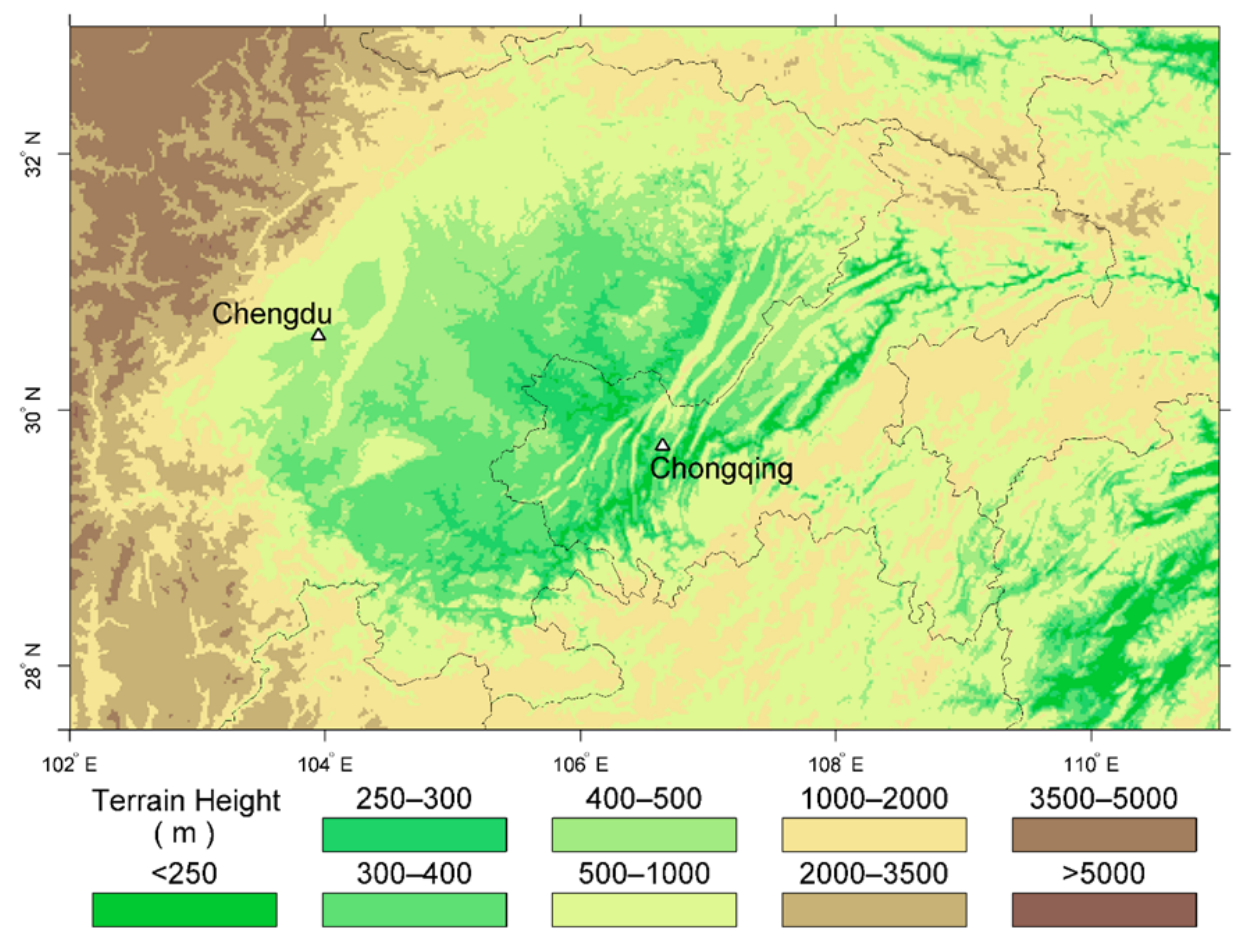

Fig. 1. Terrain height of Sichuan Basin and the location of Chengdu and Chongqing.

atmospheric circulation patterns, wintertime atmospheric extinction and meteorological parameters in Chengdu and Chongqing; (3) develop an improved method to discriminate synoptic signals from non-synoptic signals in time series of atmospheric extinction; and (4) examine the contribution of synoptic signals to the variations of wintertime atmospheric extinction in these two cities during 2001-2016.

\section{DATA AND METHODS}

\section{Meteorology and Visibility Data}

The study area contains mountain regions with high elevations. The $850 \mathrm{hPa}$ geopotential height (HGT) data, instead of commonly used mean sea level pressure, were thus used to drive the CTC. The gridded $850 \mathrm{hPa}$ HGT fields for the period of December 2000 to February 2016 were extracted from the National Center for Environmental Prediction (NCEP) FNL (Final) operational global analysis data (in $1^{\circ} \times 1^{\circ}$ horizontal resolution). All the HGT fields covering the domain of $20-40^{\circ} \mathrm{N}$ and $90-120^{\circ} \mathrm{E}$ at $00 \mathrm{UTC}$ in December, January and February were used in the CTC analysis. Besides, the PBLH fields from the FNL data at 06 UTC were used to represent boundary layer development during daytime while the three-dimensional vertical wind speed fields at 00 UTC were also obtained to analyze atmospheric subsidence.

The hourly visibility and meteorology data of the Integrated Surface Database provided by NOAA's National Centers for Environmental Information (available at https://www1.ncdc.noaa.gov/pub/data/noaa/) for 2000 2016 were used in this study. Station 562940 and 575150 (shown as triangles in Fig. 1) were selected to represent Chengdu and Chongqing, respectively. Following the quality control strategy described in Li et al. (2016), only the surface synoptic observations (SYNOP) at $3 \mathrm{~h}$ intervals were used. The extracted variables included the visibility, temperature, dew point (Td), wind speed and direction, and precipitation. Based on these variables, $\mathrm{RH}$ (in \%) was calculated from $\mathrm{T}$ (in ${ }^{\circ} \mathrm{C}$ ) and $\mathrm{T}_{\mathrm{d}}$ (in ${ }^{\circ} \mathrm{C}$ ) using $R H \approx \exp \left[17.27\left(\frac{T_{d}}{T_{d}+237.30}-\frac{T}{T+237.30}\right)\right]$ (Murray, 1967).

The hygroscopic growth of aerosols was corrected using the calculated $\mathrm{RH}$ according to the algorithm described in Che et al. (2007). The effect of RH on extinction coefficient depends on the chemical composition of aerosol. The composition of wintertime aerosol between 2002-2014 in Sichuan Basin were seldom reported. By implementing a revised IMPROVE algorithm (Pitchford et al., 2007; Wang et al., 2017) using observed aerosol composition in 2002 (Wang et al., 2004; Yang et al., 2011) and 2014-2015 (Wang et al., 2018), we evaluated the upper limits of the relative errors caused by hygroscopic growth correction. The upper limits of relative errors ranged from $12.49 \%$ (CT 4 ) to $24.75 \%$ (CT 3 ) in Chengdu and around $11 \%$ in Chongqing (see section $\mathrm{S} 1$ of the supplementary materials for the details). Then the SEC (in $\mathrm{km}^{-1}$ ) was calculated from the corrected VIS (in $\mathrm{km}$ ) using the formula SEC $=3.912$ /VIS (Koschmieder, 1926; Li et al., 2016). Note that the SEC represent the atmospheric extinction coefficient including gaseous and aerosol contributions. Considering that the contribution of gases was likely less than 5\% in Chengdu and Chongqing (Wang et al., 2018), the variations of atmospheric extinction were analyzed without considering gaseous contributions in this research. Although it is mostly dry in winter in Chengdu 
and Chongqing, the potential influence of precipitation needs to be eliminated. Any data associated with RH higher than $90 \%$ were first excluded. The whole-day data with daily precipitation greater than $5 \mathrm{~mm}$ were then excluded. Daily, seasonal and within-CT averages were only calculated if more than $50 \%$ of the data were kept after applying the above criteria.

The temperature profiles at 00 UTC were obtained from the Integrated Global Radiosonde Archive (IGRA) of NOAA to explore atmospheric inversion. The IGRA records radiosonde observations at globally distributed stations. The available observations in Chongqing were at Station 575150 for the entire study period, while in Chengdu they were at Station 562940 for the time period before 2005 and at Station 562187 afterwards. The distance between the two stations in Chengdu is about $20 \mathrm{~km}$. The low level atmospheric inversion directly affects the vertical dispersion of air pollutants. Hence, we focused on the inversion occurred below $1500 \mathrm{~m}$ above ground level. The vertical resolution of IGRA profiles, with 3-5 layers between 0 and $1500 \mathrm{~m}$, was too low to obtain the detailed structure of temperature profiles. We thus defined the lowest inversion bottom as the height of the lowest layer at which the temperature was lower than that at the upper layer. The temperature gradient at the lowest inversion bottom was calculated using the temperatures at these two adjacent layers. The occurrence frequency, vertical distribution of the lowest inversion bottom and temperature gradient were examined for each CT.

\section{Circulation Type Classification}

Several algorithms exist in literature for classifying circulation types in climatology studies. A comparison of these algorithms did not find any superiority of one algorithm over another statically (Philipp et al., 2016). Based on the successful application of T-mode Principal Component Analysis (PCA) method in previous studies, we chose the PTT (T-mode PCA orthogonally rotated) method integrated in the software package cost733class (available at http://cost733.geo.uni-augsburg.de) to do CTC in this study. The $850 \mathrm{hPa}$ HGT of grids with altitudes above $3000 \mathrm{~m}$ were excluded in CTC processes to diminish the potential vertical extrapolation errors.

\section{Correlation Strategy for Multi-year Observations}

The Pearson correlation was implemented to examine the relationships between daily averaged SEC and local meteorological parameters for each CT. However, for multiyear observations the correlations might be overwhelmed by the interannual variations of SEC and meteorological parameters. The original daily averaged time series have to be detrended before correlation analysis (Tai et al., 2010; Li et al., 2014). In this study, the relative anomalies (V) of SEC and meteorological parameters were invoked in the correlation and defined as:

$$
\mathrm{V}_{\mathrm{X}, \mathrm{dnm}}=\frac{\mathrm{X}_{\mathrm{dnm}}-\overline{\mathrm{X}_{\mathrm{nm}}}}{\overline{\mathrm{X}_{\mathrm{nm}}}}, \mathrm{X}=\mathrm{SEC}, \mathrm{RH}, \mathrm{WS}, \mathrm{PBLH}, \text { or T }
$$

where $\mathrm{V}_{\mathrm{X} \text {,dnm }}$ is the variable at the d-th day in year $\mathrm{n}$ (e.g., year 2001 means from December 2000 to February 2001) for the $\mathrm{m}$-th $\mathrm{CT}$, and $\overline{\mathrm{X}_{\mathrm{nm}}}$ is seasonal mean of $\mathrm{X}$ in year $\mathrm{n}$ for the m-th CT.

\section{Modified Method for Discriminating Synoptic Signals from Non-synoptic Signals}

The seasonal mean SEC time series for the winters from 2001 to 2016 (observed signal, $\overline{\mathrm{SEC}_{\mathrm{n}}}$ ) were decomposed into overall synoptic signals $\left(\mathrm{S}_{\mathrm{n}}\right)$ and non-synoptic signals $\left(\mathrm{E}_{\mathrm{n}}\right)$. Following Comrie (1992) and Hegarty et al. (2007), the synoptic signals have the following form:

$\mathrm{S}_{\mathrm{n}}=\frac{\sum_{\mathrm{m}=1}^{\mathrm{M}}\left(\overline{\mathrm{SEC}_{\mathrm{m}}}+\Delta \mathrm{SEC}_{\mathrm{nm}}\right) \mathrm{F}_{\mathrm{nm}}}{\sum_{\mathrm{m}=1}^{\mathrm{M}} \mathrm{F}_{\mathrm{nm}}}$

where $F_{n m}$ is the number of occurrence days in year $n$ for the m-th CT, $\overline{\mathrm{SEC}_{\mathrm{m}}}$ is the 16-year winter average of SEC for the $\mathrm{m}$-th $\mathrm{CT}$, and $\triangle \mathrm{SEC}_{\mathrm{nm}}$ is the anomaly of seasonal mean SEC in year $n$ for the $m$-th CT. On the right side of Eq. (2) the first term corresponds to the interannual variations of the occurrence frequencies (synoptic occurrence signal, $\mathrm{O}_{\mathrm{n}}$ ), and the second term to the within-type variations of circulation intensity and meteorological parameters.

In Hegarty et al. (2007) and Zhang et al. (2013), $\Delta \mathrm{SEC}_{\mathrm{nm}}$ was calculated from a linear fit between SEC anomalies and selected CII for each CT. Here, two modifications were made on the $\triangle \mathrm{SEC}_{\mathrm{nm}}$ term. One was that the linear fitting was implemented for detrended time series (relative anomalies) of SEC and then $\triangle \mathrm{SEC}_{\mathrm{nm}}$ was calculated from the derived relative anomalies. The other one was that a number of meteorological parameters, instead of single CII, was used to represent the within-CT variations of circulation intensity. The main steps of calculating $\triangle \mathrm{SEC}_{\mathrm{nm}}$ term are listed in section S2 of the supplementary materials.

According to the results of Comrie (1992), the decreases in the synoptic signals equal to the increases in the nonsynoptic signals. Hence, the derived non-synoptic signals can be determined by:

$\mathrm{E}_{2001}=\overline{\mathrm{SEC}_{\mathrm{m}}}-\mathrm{S}_{2001}$

$\mathrm{E}_{\mathrm{n}}=\mathrm{E}_{\mathrm{n}-1}+\left(\overline{\mathrm{SEC}_{\mathrm{n}}}-\overline{\mathrm{SEC}_{\mathrm{n}-1}}\right)-\left(\mathrm{S}_{\mathrm{n}}-\mathrm{S}_{\mathrm{n}-1}\right), \mathrm{n}=2002, \ldots$,

2016

\section{RESULTS AND DISCUSSION}

\section{Main Circulation Patterns Influencing the Sichuan Basin}

A total of eight CTs were obtained by adopting the CTC processes for the winters during 2001-2016 over the Sichuan Basin, but $98.8 \%$ of all the days were belonged to four of the eight CTs. Hence, the four dominant circulation patterns (noted as CT 1-4 below) were selected for further analysis. The characteristics of $850 \mathrm{hPa}$ HGT, sea-level pressure (SLP) and $10 \mathrm{~m}$ wind fields are depicted in Fig. 2. CT 1 occurred most frequently, accounting for $38.6 \%$ of the winter days, while CTs 2-4 accounted for $21.1 \%$, 
(a) CT 1, 38.57\%

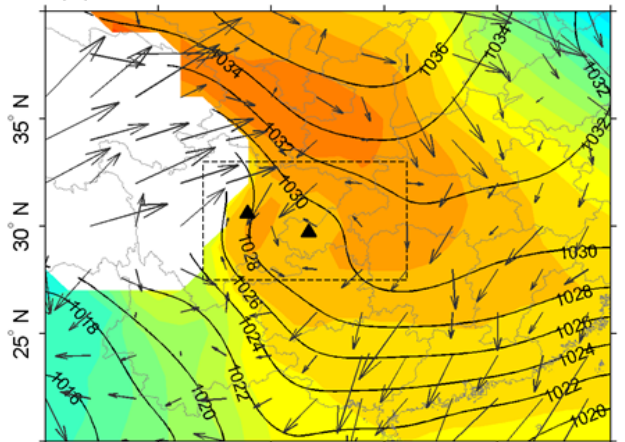

(c) CT 3, $19.67 \%$

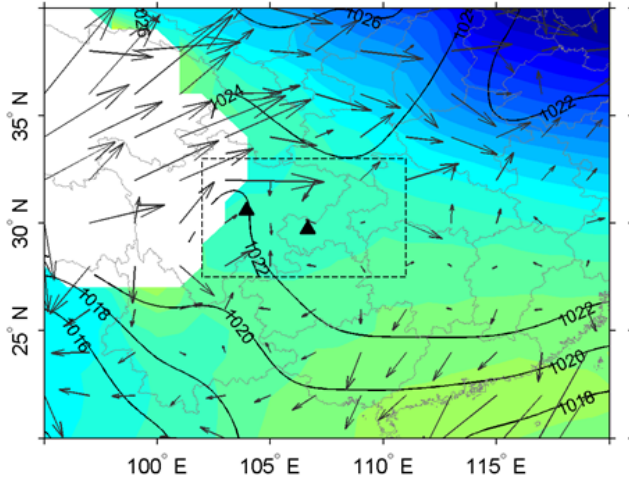

1450

1500 (b) CT 2, $21.12 \%$

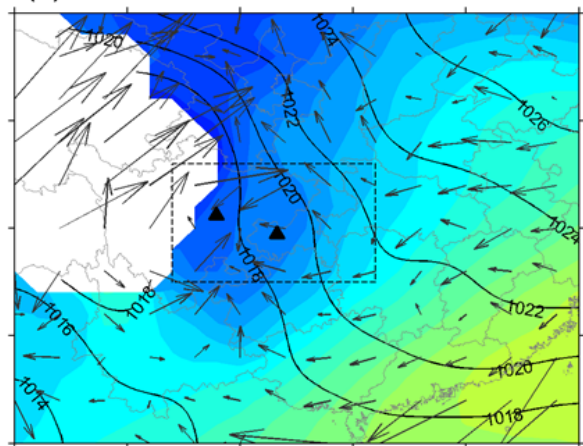

(d) CT 4, $19.46 \%$

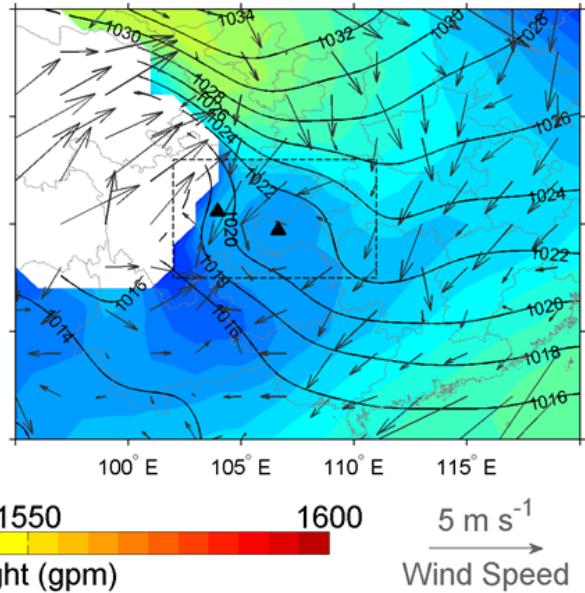

Fig. 2. Circulation characteristics of the predominant CTs for the winter in 2001-2016. The colored shadings and black contour lines are the within-CT mean $850 \mathrm{hPa}$ geopotential height in gpm and mean sea-level pressure in hPa, respectively. The gray vectors are the $10-\mathrm{m}$ wind fields. The triangles are the locations of Chengdu (west) and Chongqing (east). The number in the title is the occurrence frequencies of corresponding CT. The dashed square represents the region of Sichuan Basin. The blank area is the plateau region with altitude higher than $3000 \mathrm{~m}$.

$19.7 \%$ and $19.5 \%$, respectively. For CT 1, a strong high pressure was centered to the north of Sichuan Basin in terms of both $850 \mathrm{hPa}$ HGT and SLP. For CT 2, Sichuan Basin is located at the southeast edge of a low-pressure system at $850 \mathrm{hPa}$ and in the rear of a high-pressure system at sea level. CT 3 was associated with weak and unique high-pressure system prevailing from sea level to $850 \mathrm{hPa}$. CT 4 represented local low-pressure system controlling at $850 \mathrm{hPa}$ and high-pressure system to the north at sea level. Due to the basin topography, the $10 \mathrm{~m}$ wind velocity in Sichuan Basin was distinctly lower than the surrounding areas (Ye and Gao, 1979). Within the basin, the wind velocity in the plain regions was higher than that in the mountainous regions. The average patterns of wind direction in Sichuan Basin were similar for all CTs, showing cyclonic circulations.

\section{Impact of Circulation Patterns on SEC and Meteorological Parameters}

The means, medians, $25^{\text {th }}$ and $75^{\text {th }}$ percentiles, and extreme limits of SEC for each CT in Chengdu and Chongqing are presented in Fig. 3 while the corresponding mean values of SEC, RH, WS, PBLH and $\mathrm{T}$ are listed in Table 1. In Chengdu, CT 3 had the highest and CT 4 had the lowest
SEC with a mean value (with $\pm 1 \sigma$ ) of $1.09 \pm 0.67$ and 0.73 $\pm 0.51 \mathrm{~km}^{-1}$, respectively. The mean SEC for CT $2(1.02 \pm$ $0.85 \mathrm{~km}^{-1}$ ) was slightly lower than that for CT 3 . The CT 1 was related to medium pollution levels, with the mean SEC of $0.84 \pm 0.73 \mathrm{~km}^{-1}$. In Chongqing, the same descending order of mean SEC was observed, i.e., CT $3(1.10 \pm 0.80)$ $>$ CT $2(1.02 \pm 0.57)>$ CT $1(1.00 \pm 0.55)>$ CT $4(0.89 \pm$ $0.54)$, but with smaller between-CT differences than those in Chengdu. These averages for different CTs were significantly different at 0.05 level except for CT 2 and CT 3 in Chengdu and CT 1 and CT 2 in Chongqing. The percentiles showed similar patterns in terms of between-CT differences in most cases. The only exception was between CT 2 and CT 3 in Chengdu which showed opposite trends between the median and mean values, i.e., CT 3 had lower median but higher mean than CT 2, implying more heavily polluted events from CT 3 than CT 2 in Chengdu. Furthermore, the probability distribution of SEC showed higher SECs for CT 3 and CT 2 (see section S3 of the supplementary materials). In conclusion, the weak highpressure system (CT 3) and local low-pressure system (CT 4) were responsible for the highest and lowest SEC, respectively. When the study areas were on the edge of northerly centered high (CT 1)- or low (CT 2)-pressure 


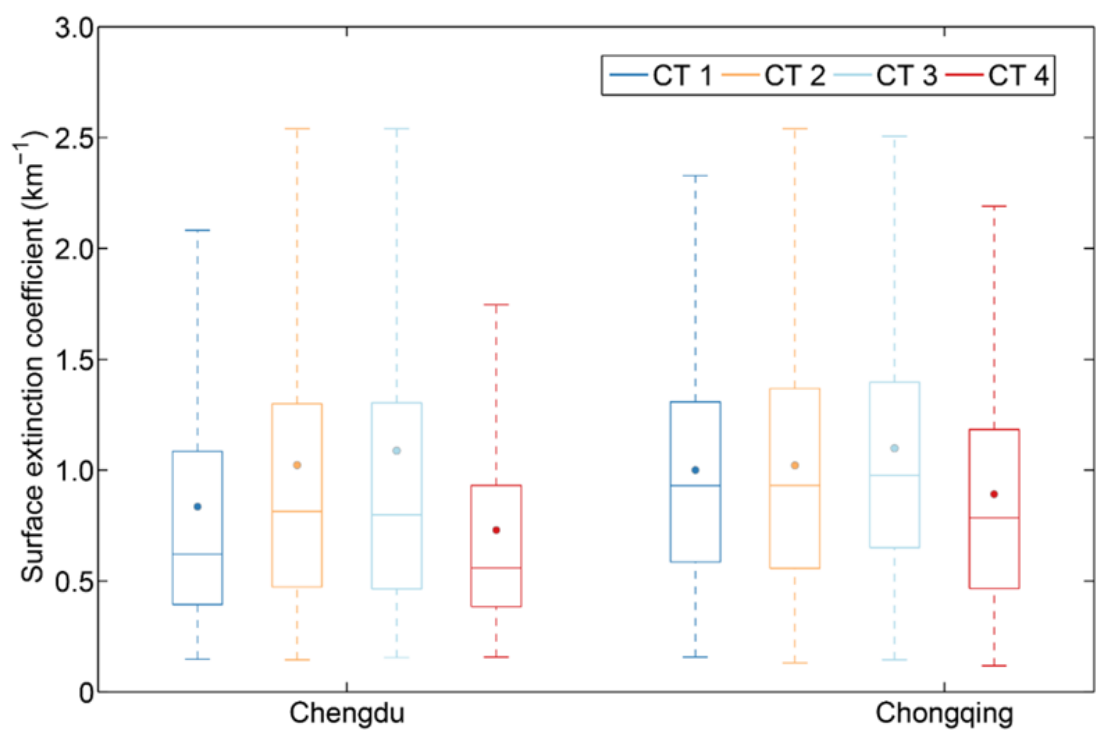

Fig. 3. The surface extinction coefficient for each $\mathrm{CT}$ in Chengdu and Chongqing. The upper limit, center bar, lower limits of the box are $25^{\text {th }}, 50^{\text {th }}$ and $75^{\text {th }}$ percentiles, respectively. The upper and lower whiskers are the maximum and minimum values. The dots represent the average values.

systems, air pollution was in medium level compared to that for CT 3 and CT 4.

The frequency and mean wind speed (WS) from 16 wind directions for each CT in Chengdu and Chongqing are presented in Fig. 4. In Chongqing, both the wind direction frequency and WS changed slightly with different CTs. Mean WS for different CTs varied within $0.1 \mathrm{~m} \mathrm{~s}^{-1}$, ranging from 1.42 to $1.51 \mathrm{~m} \mathrm{~s}^{-1}$. This indicates that WS in Chongqing was likely dominated by local complicated topography. In Chengdu, WS ranged from $1.94 \pm 1.04 \mathrm{~m} \mathrm{~s}^{-1}$ (associated with CT 3) to $2.49 \pm 1.46 \mathrm{~m} \mathrm{~s}^{-1}$ (associated with CT 4). WS in Chengdu was controlled by large-scale circulation and also impacted by surrounding topography, as discussed in previous studies (Ye and Gao, 1979; Wang and Tan, 2014; Feng et al., 2016). The small pressure gradient resulted from the weak high-pressure system could explain the minimum WS in CT 3. High WS associated with CT 4 can be a result of two flows, one northerly flow over Chengdu induced by low-pressure system and another one originated from the high-pressure system to the northwest along the northern and western edges of the basin. Similar to the latter flow, for CT 2 the topography turned the easterly flow into northerly flow with smaller WS over Chengdu. Therefore, in Fig. 4(a) the pattern of wind direction frequency for CT 2 was similar to that for CT 4, but the WS was much smaller especially for the northerly wind. In CT 1 more southerly winds were observed because the strong high-pressure system caused more geostrophic features for the air flow.

Horizontal dispersion was quantified by considering air mass stagnation, recirculation and ventilation following the method proposed by Allwine and Whiteman (1994). The displacement (L) of the air mass in any 24-hour period was calculated from local average wind vector. Similarly, the air moving distance (D) was calculated from the scalar average of WS during the same period. The recirculation index can be expressed as $R=1-L / D$. A value of 1 for $R$ represents no net transport and a value of 0 means constant flow direction. Recirculation and stagnation were identified as $\mathrm{R} \geq 0.6$ and $\mathrm{D} \leq 130 \mathrm{~km}$ (scalar mean WS is about $1.5 \mathrm{~m} \mathrm{~s}^{-1}$ ), respectively. Ventilation was identified as $\mathrm{D} \geq$ $250 \mathrm{~km}$ (with a scalar mean WS of about $2.9 \mathrm{~m} \mathrm{~s}^{-1}$ ) and $\mathrm{R}$ $\leq 0.2$ (Ye et al., 2016). The occurrence frequencies of stagnation, recirculation and ventilation for each $\mathrm{CT}$ in Chengdu and Chongqing are listed in Table 2.

In Chongqing, stagnation occurred frequently while ventilation rarely happened due to calm winds. The relatively lower frequency of stagnation for CT 4 than for other CTs was in accordance with the SEC values in Table 1. In Chengdu, stagnation occurred much less but ventilation occurred more than in Chongqing. In both cities, the highest ventilation and lowest stagnation frequencies were associated with CT 4, which were consistent with the low SEC for this CT. Conversely, the frequent stagnation and no ventilation associated with CT 3 were responsible for the high SEC. At both cities, the frequencies of recirculation were higher for CT 3 than for other CTs due to the weak weather system for CT 3, under which condition local circulations with diurnal features, such as mountain-valley breeze and urban heat island breeze, became dominant.

The patterns of pressure vertical velocities for each CT are presented in Fig. 5. The study area lies at the lee side of the Tibetan Plateau, and thus subsidence features are expected. However, the specific topography in the basin area favors the formation of cyclonic-like circulation in the low-level troposphere, as discussed above. This prevailing circulation pattern induces convergence and further causes ascending flow in the center of the basin area. Hence, strong subsidence was observed around Chengdu and Chongqing (Fig. 5), which are located at the edges of the basin, and there was always an updraft zone between these two cities. Chengdu was in the kernel of the western subsidence zone 


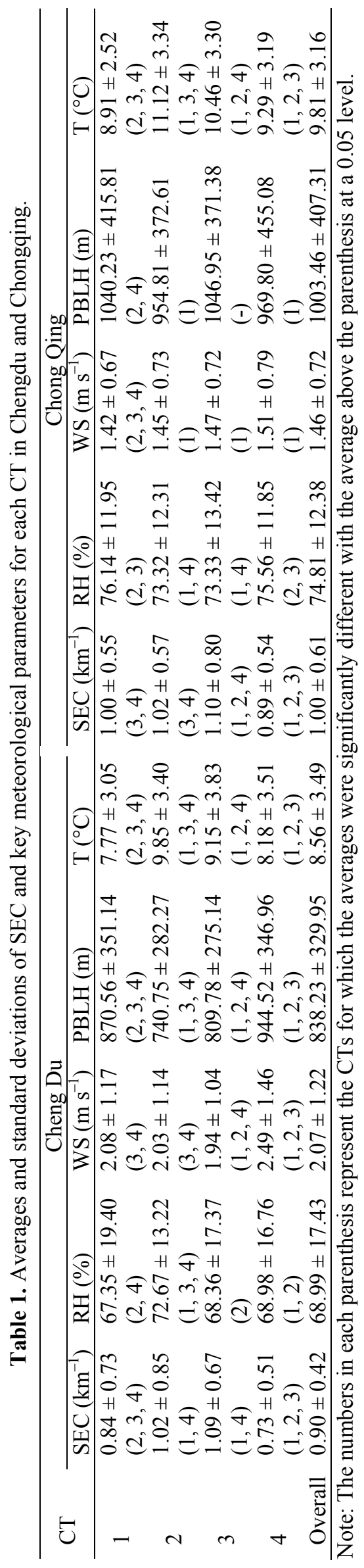

and exhibited strong downdraft while Chongqing was closer to the updraft zone. The strongest and weakest subsidence occurred in CT 3 and CT 4, respectively. Chongqing was even in the updraft zone when CT 4 prevailed. These circulation patterns contributed to the high SEC for CT 3 and low SEC for CT 4 in both cities.

The mean PBLH for each CT in the study area are presented in Fig. 6. Generally, a low PBLH belt existed in the western and southern basin area, which might be caused by the subsidence of lee effect. As discussed above, there was always an ascending region caused by the largescale circulation and topography. As a result, a high PBLH region extended from northeastern corner to the center of the basin. Chengdu and Chongqing are situated at the edge of low belt and high region, respectively. Hence, the mean PBLH of Chongqing was higher than that in Chengdu as listed in Table 1. The between-CT comparison of SEC and PBLH showed that SEC increases with decreasing PBLH in Chengdu, but no such trend existed in Chongqing. This further implies that the influence of atmospheric circulation was weaker in Chongqing than in Chengdu.

The temperature in Chengdu and Chongqing varied synchronously with different CTs. The strong northerly cold air in CT 1 caused the lowest temperature. The easterly flow in CT 2 brought warmer air mass into the study area, so the highest temperature was associated with $\mathrm{CT} 2$. The temperature in CT 3 was higher than that in CT 4 because there was more advection from the north and more cloud cover in CT 4 (Fig. 5).

The between-CT variations of RH and $\mathrm{T}$ in Chengdu were different than those in Chongqing according to Table 1. In Chongqing, the between-CT mean RH and T for different CTs were negatively correlated. This might be related to the fact that Chongqing was less influenced by the large-scale circulation as demonstrated by the other parameters. Hence, the water vapor content in the air should be stable for different CTs. In Chengdu, evidently water vapor advection could be noticed in CT 1 and CT 2 . Specifically, severe influence of the northerly cold and dry air mass caused the lowest $\mathrm{T}$ and lowest RH in CT 1, and the easterly flow resulted in the highest $\mathrm{T}$ and highest $\mathrm{RH}$ in CT 2. In terms of between-CT mean, the relations between the SEC and RH, T were complicated in both cities.

Temperature inversion is another factor influencing air quality through suppressing vertical mixing of pollutants. Fig. 7 presents the occurrence frequencies of inversion at different altitudes and with different temperature gradients for each CT. The frequency of inversion was $43.1 \%$, $37.6 \%, 62.9 \%$ and $33.1 \%$ in Chengdu, and $10.9 \%, 17.0 \%$, $35.1 \%$ and $8.4 \%$ in Chongqing for CT 1, 2, 3 and 4 , respectively. Besides the higher frequencies of inversion found in Chengdu than Chongqing, the inversion height was much lower and the inversion strength (temperature gradient) was much higher in Chengdu. The frequency of inversion was directly related to the atmospheric circulation patterns. For example, inversion occurred most frequently in CT 3 because the high-pressure system caused clear weather and facilitated nocturnal radiative cooling, which favored the formation of surface inversion. Besides, the 


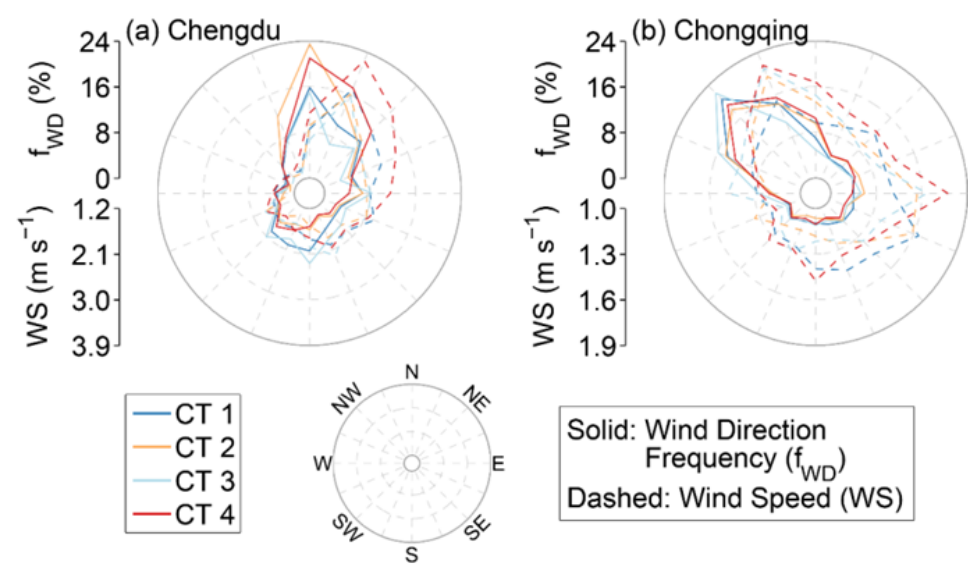

Fig. 4. The frequency and mean wind speed at different wind direction for the 4 CTs in (a) Chengdu and (b) Chongqing.

Table 2. The occurrence frequency of stagnation, recirculation and ventilation for 4 CTs in Chengdu and Chongqing.

\begin{tabular}{lllll}
\hline \multirow{2}{*}{ Site } & \multirow{2}{*}{ CT } & \multicolumn{3}{c}{ Occurrence Frequency (\%) } \\
\cline { 3 - 5 } & & Stagnation & Recirculation & Ventilation \\
\hline Chengdu & 1 & 15.53 & 15.53 & 11.65 \\
& 2 & 13.46 & 5.77 & 0 \\
& 3 & 16.67 & 29.17 & 32.53 \\
Chongqing & 4 & 7.23 & 12.05 & 12.45 \\
& 1 & 13.52 & 15.29 & 0 \\
& 2 & 73.98 & 20.07 & 0.45 \\
& 3 & 71.36 & 15.91 & 0 \\
\end{tabular}

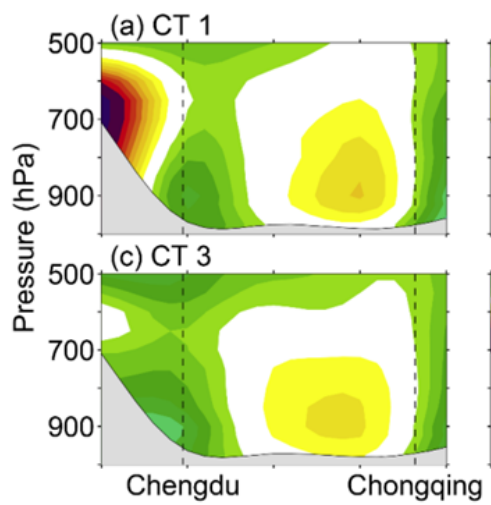

(b) CT 2

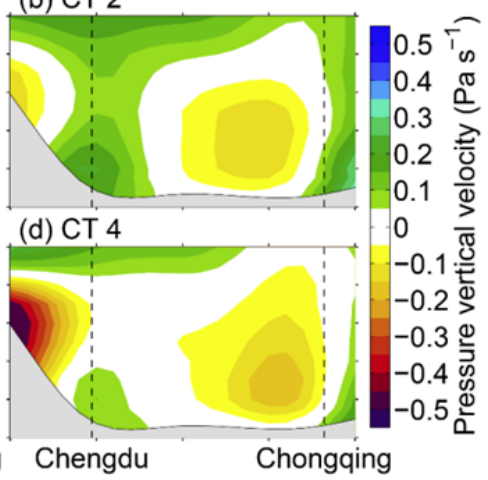

Fig. 5. The pressure vertical velocity distributions on the cross section passing through Chengdu and Chongqing for the 4 CTs. The gray areas represent underlying topography. The left and right dashed lines label the locations of Chengdu and Chongqing, respectively.

strong subsidence associated with the high-pressure system led to more upper-level inversion. On the contrary, the low-pressure system and weak subsidence in CT 4 led to the lowest frequency of inversion.

In summary, differences in SEC and meteorological parameters between different CTs were much larger in Chengdu than Chongqing, indicating stronger influence of atmospheric circulation in Chengdu. The synoptic dynamic factors, such as wind, subsidence, inversion and PBLH, dominated the between-CT variations in SEC in both cities.
No apparent impact of the chemistry-related factors (RH and $\mathrm{T})$ was recognized for causing between-CT SEC variations.

\section{Within-CT Correlations between SEC and Meteorological Parameters}

The within-CT analysis is capable of capturing the key influencing parameters by diminishing the impact of circulation patterns. In any given circulation pattern, the variations of meteorological parameters are mainly caused by the intensity of dominant weather systems. The correlation 
coefficients between the relative anomalies of SEC and meteorological parameters, including $\mathrm{RH}, \mathrm{WS}, \mathrm{PBLH}$ and $\mathrm{T}$, for each CT are listed in Table 3.

In Chengdu, SEC negatively correlated with WS for CT 1, CT 2 and CT 4 due to the effect of horizontal dispersion, and only weakly correlated with WS for CT 3 due to calm wind and frequent stagnation. Due to the strong subsidence over Chengdu, vertical dispersion of pollutants was suppressed. Only CT 1 and CT 4 showed significant negative correlation between PBLH and SEC. SEC positively correlated with $\mathrm{RH}$ for all the $\mathrm{CT}$, which could be explained by several RH-dependent processes in the atmosphere. For
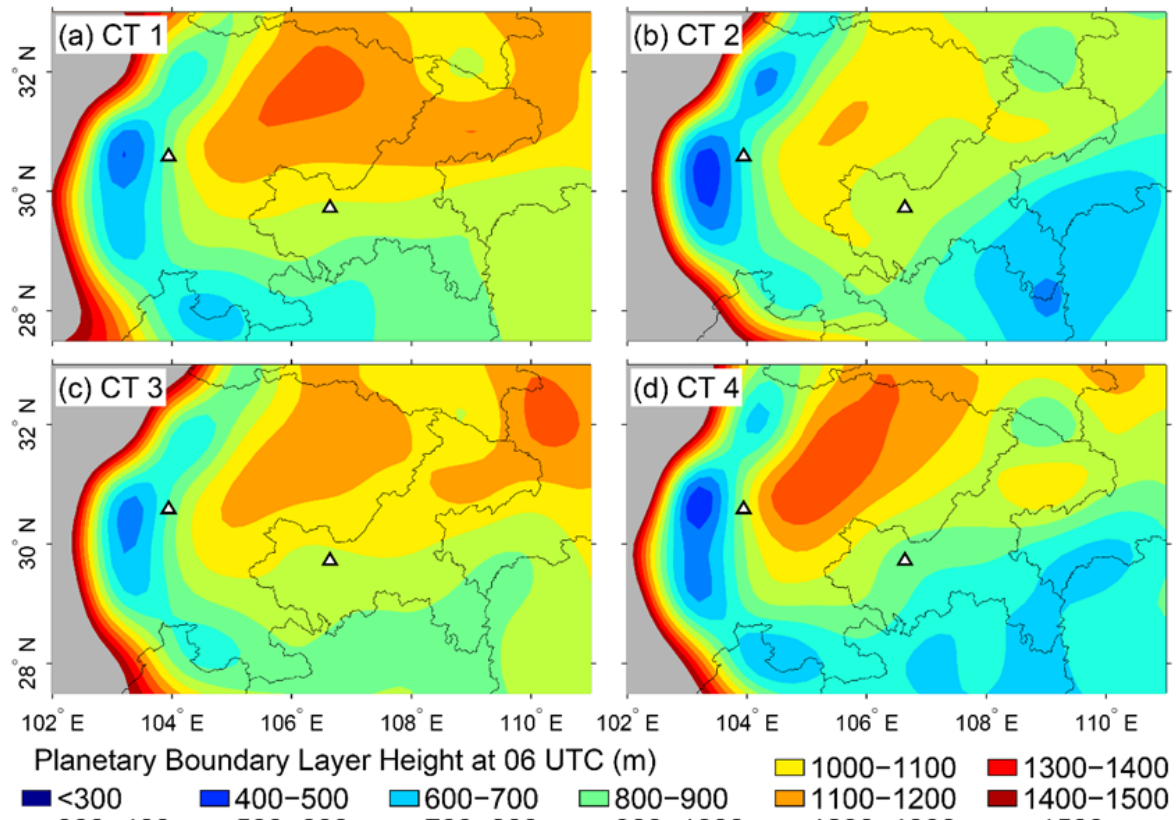

$\square=300-400 \square 500-600 \quad \square 700-800 \quad \square 900-1000 \quad \square 1200-1300 \square>1500$

Fig. 6. The within-CT mean planetary boundary layer height at 06 UTC for each CT. The triangles mark the location of Chengdu (west) and Chongqing (east).

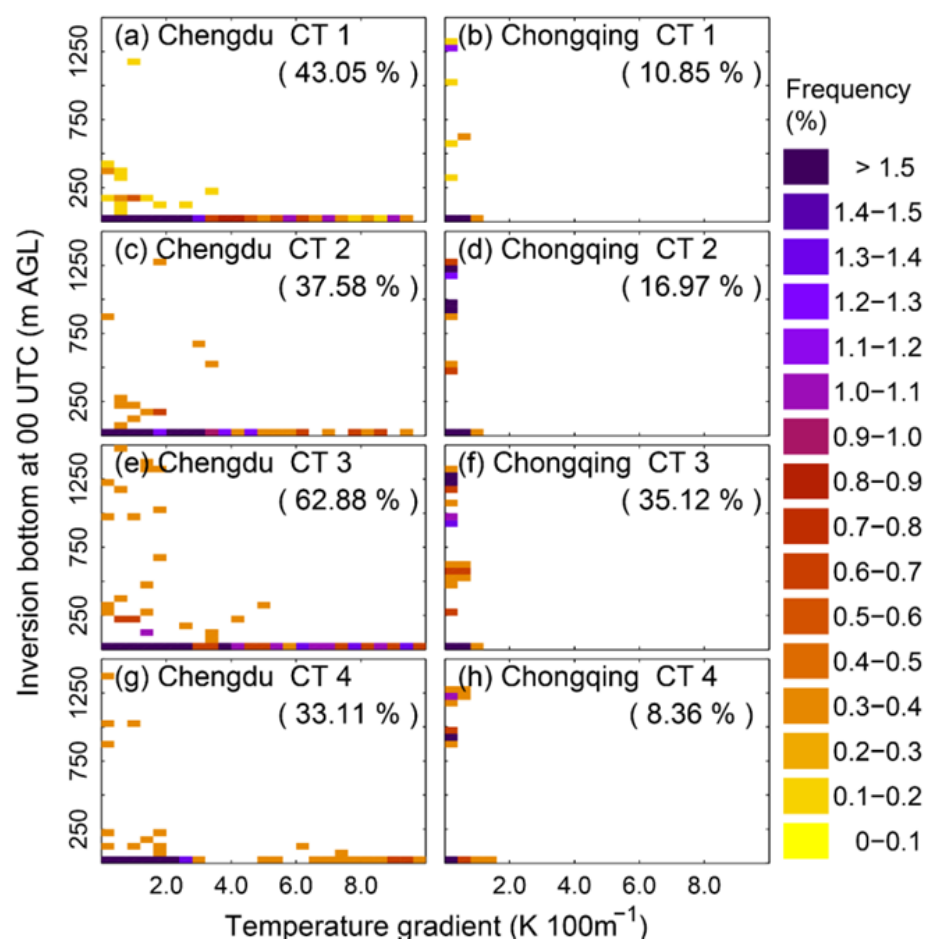

Fig. 7. The occurrence frequency of temperature inversion at different height and with different temperature gradient for each CT in Chengdu and Chongqing. The colored shadings are the frequency for corresponding bins of inversion bottom and temperature gradient at inversion bottom. The parenthesized numbers are the overall frequencies of inversion for each CT. 
Table 3. The within-CT correlation coefficients between the relative anomalies of SEC and meteorological parameters for each CT in Chengdu and Chongqing.

\begin{tabular}{|c|c|c|c|c|c|c|c|c|}
\hline \multirow{2}{*}{ CT } & \multicolumn{4}{|c|}{ Chengdu } & \multicolumn{4}{|c|}{ Chongqing } \\
\hline & RH & WS & PBLH & $\mathrm{T}$ & RH & WS & PBLH & $\mathrm{T}$ \\
\hline 1 & 0.34 & -0.24 & -0.16 & 0.09 & 0.19 & -0.23 & -0.11 & 0.23 \\
\hline 2 & 0.13 & -0.36 & 0.08 & 0.08 & 0.35 & -0.27 & -0.22 & 0.11 \\
\hline 3 & 0.46 & -0.03 & -0.04 & -0.22 & 0.34 & -0.26 & -0.14 & -0.03 \\
\hline 4 & 0.18 & -0.34 & -0.15 & 0.04 & 0.17 & -0.38 & -0.02 & 0.23 \\
\hline Overall & 0.21 & -0.27 & -0.11 & -0.02 & 0.24 & -0.22 & -0.08 & 0.10 \\
\hline
\end{tabular}

Note: The bold black and gray data imply the correlations are significant at level of 0.01 and 0.05 , respectively.

example, high RH enhances aqueous-phase reactions of sulfate (Sun et al., 2013) and facilitates the formation of ammonium nitrate (Tai et al., 2010; Seinfeld and Pandis, 2016). High RH also modulates partitioning of semivolatile species into particulate phase $(\mathrm{Hu}$ et al., 2008; Zhang et al., 2015b). SEC correlated weakly and positively with temperature for CT 1, CT 2 and CT 4 and negatively for CT 3. The weak positive correlation could be a competitive effect between strong photochemical reactions and restrained condensation of volatile compounds under high-temperature condition (Tai et al., 2010; Pateraki et al., 2012). The significant negative correlation in CT 3 should be a result of the negative correlation between $\mathrm{RH}$ and temperature under the weak weather system. Dispersion is important in modulating SEC in strong weather systems (CTs 1, 2 and 4) while chemical process is more critical in weak systems (CT 3).

Correlation analysis results in Chongqing were similar to those in Chengdu for each individual meteorological parameter, but the within-CT combination of meteorological parameters and between-CT discrepancies differed from each other between the two cities. The impacts of dispersion and chemical processes were equally important for every CT in Chongqing due to weak influence of large-scale circulation. Specifically, the significant influence of $\mathrm{T}$ on SEC in strong weather systems (CT 1 and CT 4) and WS/PBLH in weak weather systems (CT 3) found in Chongqing was not found in Chengdu.

\section{Interannual Variation of SEC and Meteorological Parameters}

Fig. 8 presents the interannual variations of CT occurrence days $\left(F_{n m}\right)$ in winters of 2001-2016. The ranges of occurrence days for CTs 1-4 were 16-49, 12-27, 4-29, and 9-32 days, respectively. The interannual variations of SEC and meteorological parameters are shown in Fig. 9 for Chengdu and in Fig. 10 for Chongqing. Seasonal mean SEC in Chengdu first increased before 2005 and then decreased starting in 2006. The largest increase occurred in 2005 with SEC being $0.583 \mathrm{~km}^{-1}$ higher than that in 2004 , and then a steep decrease of $-0.488 \mathrm{~km}^{-1}$ happened in 2006, followed by a gradual decrease until 2015 and an accelerated decrease in 2016 (by $-0.301 \mathrm{~km}^{-1}$ compared to that in 2015) (Table 6). The variation trends of seasonal mean SEC showed an increase of $2.745 \mathrm{~km}^{-1}$ per decade during 2001-2005 and a decrease of $-0.260 \mathrm{~km}^{-1}$ per decade during 2005-2016 (Table 7). Seasonal mean SEC for CT 1,
CT 2 and CT 4 showed similar trends to the overall mean SEC, while that for CT 3 showed a distinct increasing trend during 2009-2012. The variation ranges of SEC were much larger for CT 2 and CT 3 than CT 1 and CT 4.

Different interannual variations were observed in Chongqing than in Chengdu. The whole study period could be divided into 3 intervals: a declining one from 2001 to 2009, an increasing one from 2009 to 2014, and then a declining one again from 2014 to 2016, resulting the lowest seasonal mean SEC in 2009 and the highest in 2014. The magnitudes of interannual variations were much lower than those in Chengdu. The maximum interannual increase and decrease of SEC were 0.176 and $-0.162 \mathrm{~km}^{-1}$, respectively. The decreasing trends were -0.338 and $-1.297 \mathrm{~km}^{-1}$ per decade during 2001-2009 and 2014-2016, respectively, while the increasing trend during 2009-2014 was $0.758 \mathrm{~km}^{-1}$ per decade. The between-CT differences of interannual variations were much smaller than those in Chengdu.

Compared with SEC, the overall interannual variations of meteorological parameters were more monotonous in the whole study period. In both Chengdu and Chongqing $\mathrm{RH}$ showed a declining trend. WS retained an increasing trend in Chengdu and a decreasing one in Chongqing. PBLH increased before 2007 and then slightly decreased at both cities. The interannual variations of temperature in Chongqing were almost the same as those in Chengdu but with larger magnitudes. Temperature in the study area seemed to be stable during 2001-2016 despite significant fluctuations. The differences of the interannual variation trends between CTs were small for $\mathrm{RH}$ and temperature, but significant for WS and PBLH.

The relationships between the variation trends of SEC and meteorological parameters were complicated because of additional dominant influences of non-synoptic factors (such as anthropogenic emissions). As an example, the deceasing RH and increasing PBLH during 2001-2004 in Chongqing can lead to decreasing SEC, while the decreasing WS favors increasing SEC. The variation trends of SEC cannot be explained simply by the trends of meteorological parameters. Further analysis results are presented in the next section.

\section{Synoptic and Non-synoptic Signals and their Variation Trends}

The results of the principal component analysis on the relative anomalies of $\mathrm{RH}, \mathrm{WS}, \mathrm{PBLH}$ and $\mathrm{T}$ are listed in Table 4. For the $i^{\text {th }} \mathrm{PC}$ of the $\mathrm{m}^{\text {th }} \mathrm{CT}$, the loading of each 
meteorological parameter $\left(\sqrt{\lambda_{\mathrm{mi}}} e_{\mathrm{mi}}\right)$ and the explained variance $\left(\lambda_{\mathrm{mi}} / \sum_{\mathrm{i}=1}^{4} \lambda_{\mathrm{mi}}\right)$ are presented. Each PC represents certain weather condition, described by the combination of meteorological parameters. A higher loading implies higher impact from the corresponding meteorological parameter. The explained variance of each $\mathrm{PC}$ can be interpreted as the occurrence frequency of the corresponding weather condition. Hence, the first PC of each CT stands for the

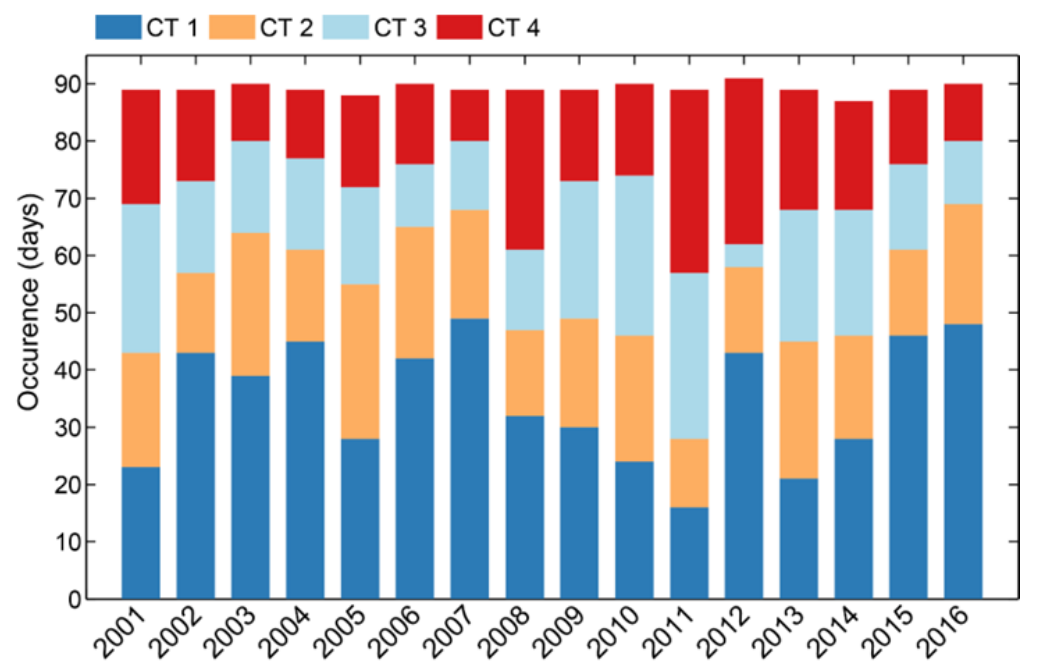

Fig. 8. The interannual variations of occurrence days in winters of 2001-2016 for each CT.

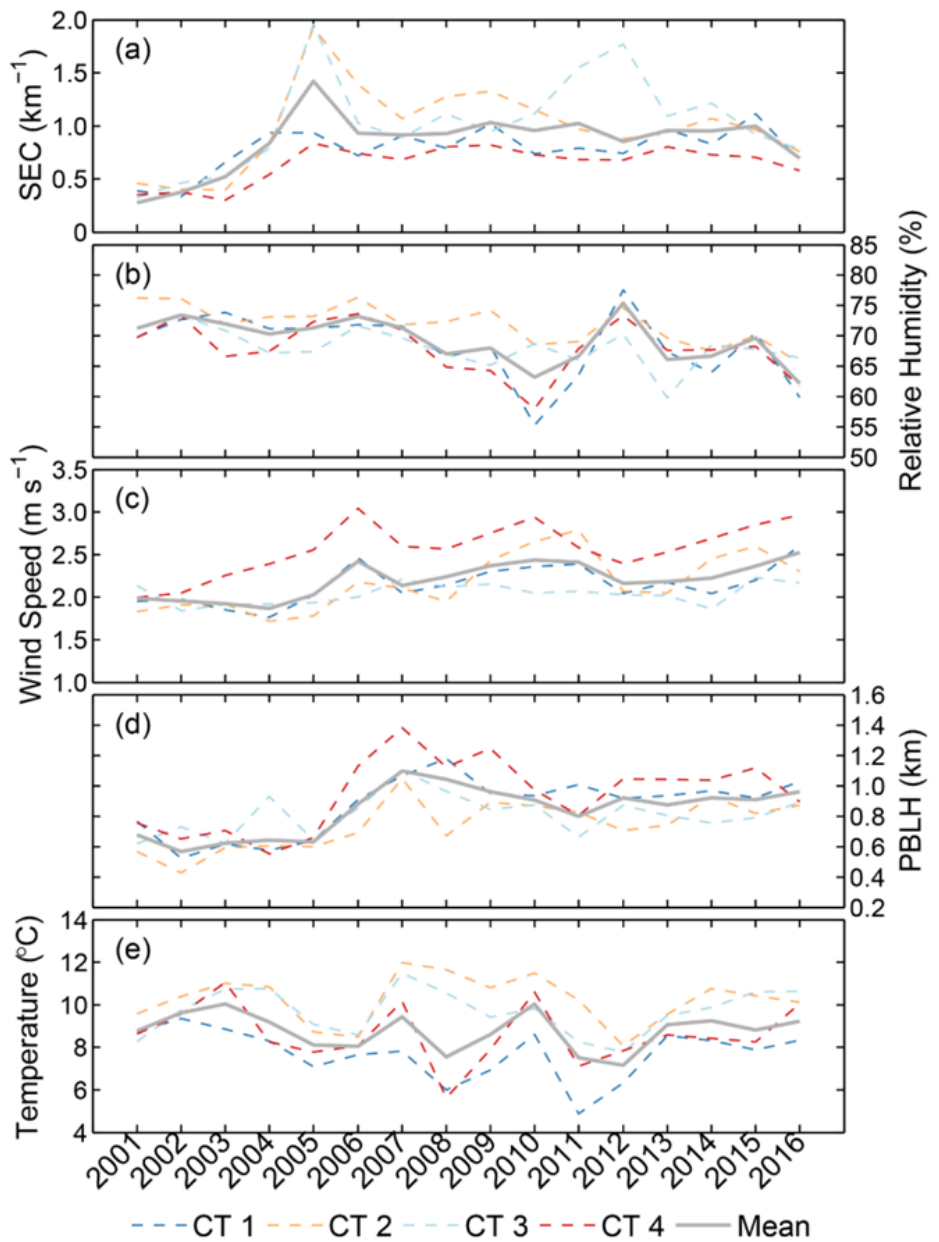

Fig. 9. The interannual variations of seasonal mean of (a) SEC, (b) RH, (c) WS, (d) PBLH, and (e) T in winters of 20012016 for each CT in Chengdu. The dashed lines are the averages for separate CTs. The gray lines are the overall averages. 


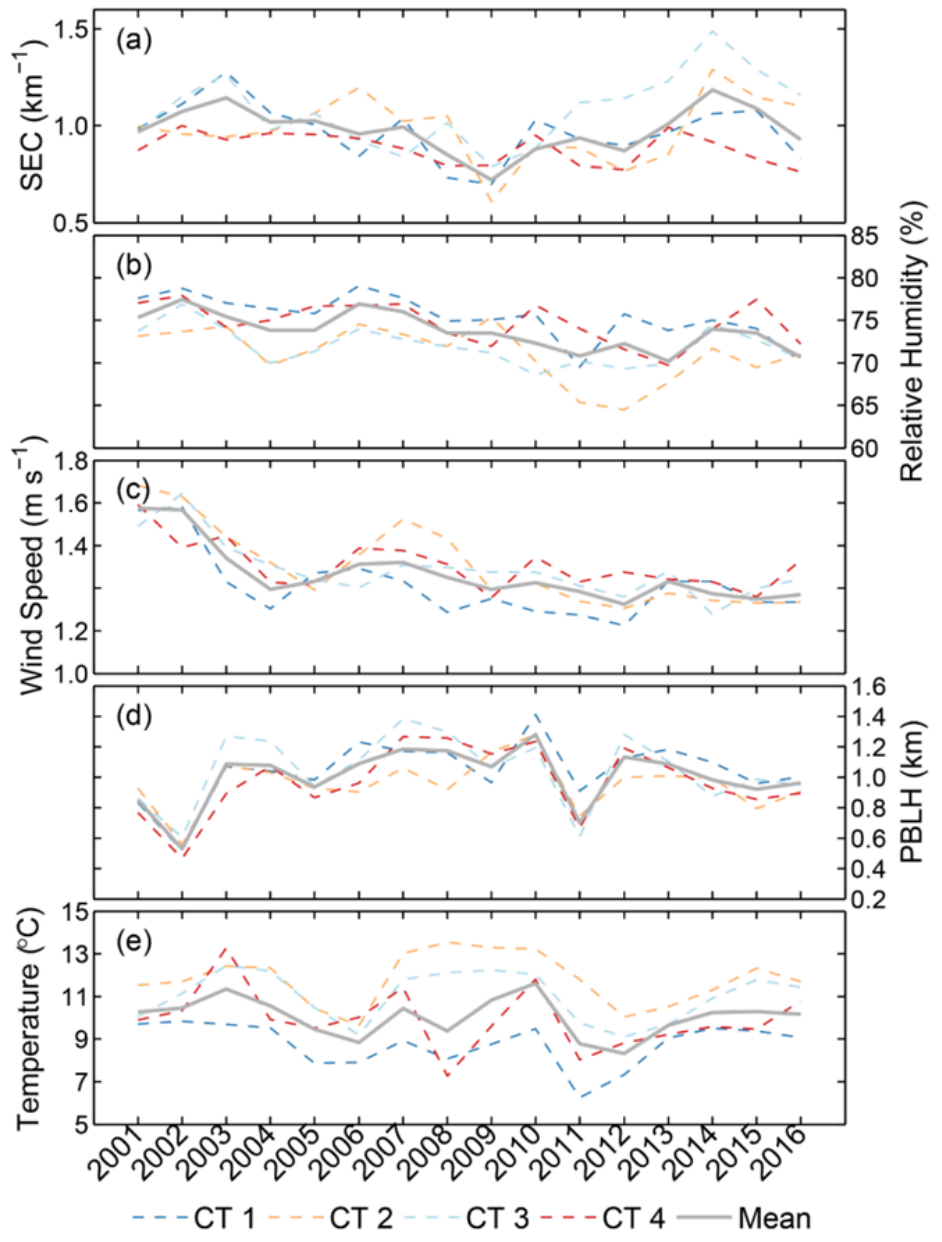

Fig. 10. The same as Fig. 9 but in Chongqing.

Table 4. The loading of meteorological parameters and explained variance (EV) of each PC for each CT in Chengdu and Chongqing.

\begin{tabular}{|c|c|c|c|c|c|c|c|c|c|c|c|}
\hline \multirow{2}{*}{$\mathrm{CT}$} & \multirow{2}{*}{$\mathrm{PC}$} & \multicolumn{5}{|c|}{ Chengdu } & \multicolumn{5}{|c|}{ Chongqing } \\
\hline & & RH & WS & PBLH & $\mathrm{T}$ & $\mathrm{EV}(\%)$ & RH & WS & PBLH & $\mathrm{T}$ & $\mathrm{EV}(\%)$ \\
\hline \multirow[t]{4}{*}{ CT1 } & PC1 & 0.744 & -0.674 & -0.590 & 0.059 & 33.96 & -0.837 & 0.228 & 0.803 & 0.165 & 35.61 \\
\hline & $\mathrm{PC} 2$ & 0.152 & -0.268 & 0.585 & 0.860 & 29.43 & -0.032 & 0.731 & -0.092 & -0.724 & 26.72 \\
\hline & PC3 & 0.505 & 0.686 & -0.125 & 0.210 & 19.63 & -0.027 & -0.625 & 0.287 & -0.667 & 22.97 \\
\hline & PC4 & 0.411 & -0.062 & 0.543 & -0.461 & 16.99 & 0.546 & 0.148 & 0.514 & 0.060 & 14.70 \\
\hline \multirow[t]{4}{*}{ CT2 } & PC1 & -0.746 & 0.076 & 0.734 & 0.740 & 41.20 & -0.788 & 0.523 & 0.644 & 0.460 & 38.04 \\
\hline & $\mathrm{PC} 2$ & 0.033 & 0.942 & -0.344 & 0.278 & 27.12 & -0.180 & -0.393 & 0.607 & -0.710 & 26.49 \\
\hline & PC3 & 0.656 & -0.055 & 0.250 & 0.419 & 16.79 & 0.286 & 0.754 & 0.055 & -0.443 & 21.25 \\
\hline & PC4 & 0.110 & 0.321 & 0.530 & -0.447 & 14.89 & -0.514 & 0.055 & -0.463 & -0.296 & 14.22 \\
\hline \multirow[t]{4}{*}{ CT3 } & PC1 & -0.578 & 0.447 & 0.773 & 0.797 & 44.15 & -0.824 & 0.630 & 0.476 & 0.483 & 38.37 \\
\hline & $\mathrm{PC} 2$ & 0.513 & 0.818 & -0.108 & 0.018 & 23.58 & 0.148 & 0.521 & -0.797 & 0.360 & 26.44 \\
\hline & PC3 & 0.635 & -0.353 & 0.390 & 0.280 & 18.94 & -0.199 & 0.437 & -0.112 & -0.798 & 21.98 \\
\hline & PC4 & -0.017 & 0.087 & 0.489 & -0.535 & 13.33 & 0.510 & 0.377 & 0.354 & 0.029 & 13.21 \\
\hline \multirow[t]{4}{*}{ CT4 } & PC1 & -0.707 & 0.133 & 0.819 & 0.371 & 33.15 & 0.850 & -0.293 & -0.735 & -0.271 & 35.52 \\
\hline & $\mathrm{PC} 2$ & 0.423 & 0.661 & -0.046 & 0.673 & 26.75 & 0.053 & -0.868 & 0.494 & -0.233 & 26.37 \\
\hline & PC3 & 0.257 & -0.739 & 0.084 & 0.570 & 23.58 & 0.124 & -0.290 & -0.084 & 0.932 & 24.39 \\
\hline & PC4 & -0.505 & -0.014 & -0.566 & 0.292 & 16.52 & 0.510 & 0.276 & 0.458 & 0.059 & 13.72 \\
\hline
\end{tabular}

main feature of the weather controlled by this circulation pattern. In Chengdu the first PC of CT 1 was characterized as low RH accompanied by high WS and PBLH, which was related to the northerly air mass invasion. This weather type should lead to positive correlations between $\mathrm{RH}$ and $\mathrm{T}$ because of the dry cold air from the north. The 
weak positive contribution of $\mathrm{T}$ in the first $\mathrm{PC}$ of $\mathrm{CT} 1$ might be resulted by the counteraction from local radiative warming. The first PCs of the other CTs in Chengdu and all the CTs in Chongqing showed more localized characteristics, namely weaker WS influences and low RH accompanied by high PBLH and T. The second, third and fourth PCs represent less frequent weather conditions, but even the lowest one explained more than $10 \%$ of the variances of these PCs, and thus was non-negligible.

The regression expressions between SEC and PCs are presented in Table 5. The regression slopes are controlled by the correlations between SEC and the dominant meteorological parameters of this PC. Hence, the results in Table 5 need to be in accordance with Tables 3 and 4. For instance, the first PC of CT 1 in Chengdu was dominated by $\mathrm{RH}, \mathrm{WS}$ and $\mathrm{PBLH}$ with positive loading for $\mathrm{RH}$ and negative loadings for WS and PBLH. Meanwhile the SEC was positively (negatively) correlated to RH (WS and PBLH) according to Table 3 . As a result, the first PC of CT 1 in Chengdu was positively correlated to SEC. The first PC of CT 2 in Chengdu was dominated by RH, PBLH and $\mathrm{T}$ with loadings of similar magnitudes. However, the correlations between SEC and these 3 parameters were weak, enabling this PC having little impact on the relative anomalies of SEC. While in the case of the third PC of CT 1 in Chengdu, the opposite influences of RH and WS led to weak correlations between SEC and this PC.

Applying the method described in Sec. 2.4, the synoptic occurrence signals, overall synoptic signals and derived non-synoptic signals were calculated and are presented in Fig. 11. The interannual variations of the observed signals $\left(\Delta \overline{\mathrm{SEC}_{\mathrm{n}}}\right)$, the synoptic occurrence signals $\left(\Delta \mathrm{O}_{\mathrm{n}}\right)$, and the overall synoptic signals $\left(\Delta \mathrm{S}_{\mathrm{n}}\right)$ are listed in Table 6 , along with the ratio $\Delta \mathrm{S}_{\mathrm{n}} / \Delta \overline{\mathrm{SEC}_{\mathrm{n}}}$, which is used to represent the contribution of atmospheric circulation to the SEC variations. In Chengdu, $\Delta \overline{\mathrm{SEC}_{\mathrm{n}}}$ fell into a wide range, from nearly 0 to $0.583 \mathrm{~km}^{-1}$. By contrast, $\Delta \mathrm{S}_{\mathrm{n}}$ was much smaller, between 0.010 and $0.077 \mathrm{~km}^{-1}$. In 8 of the 15 years, $\Delta \mathrm{S}_{\mathrm{n}}$ and $\Delta \overline{\mathrm{SEC}_{\mathrm{n}}}$ had the same sign, which means the atmospheric circulation intensified the interannual variations of SEC, while in the other 7 years the impact of the atmospheric circulation was weakening. The medians of $\Delta \mathrm{S}_{\mathrm{n}} / \Delta \overline{\mathrm{SEC}_{\mathrm{n}}}$ in intensifying and weakening years were $23.17 \%$ and $44.79 \%$, respectively. A comparison between $\Delta \mathrm{O}_{\mathrm{n}}$ and $\Delta \mathrm{S}_{\mathrm{n}}$ showed that in most years the occurrence and intensity of the circulation had opposite impacts on SEC. In Chongqing, both $\Delta \overline{\mathrm{SEC}_{\mathrm{n}}}$ and $\Delta \mathrm{S}_{\mathrm{n}}$ varied in smaller ranges than those in Chengdu. The maximum magnitudes of $\Delta \overline{\mathrm{SEC}_{\mathrm{n}}}$ and $\Delta \mathrm{S}_{\mathrm{n}}$ were 0.176 and $0.062 \mathrm{~km}^{-1}$, respectively. In more years (10 of 15) the contribution of synoptic was positive. The medians of $\Delta \mathrm{S}_{\mathrm{n}} / \Delta \overline{\mathrm{SEC}_{\mathrm{n}}}$ in intensifying and weakening years were $23.58 \%$ and $-8.02 \%$, respectively, in Chongqing. This quantitative analysis showed that in more than half of the years the impact of the atmospheric circulation intensified the interannual variations of SEC. The medians of the intensifying rate were around $23 \%$ in both Chengdu and Chongqing. Hence, the derived non-synoptic signals were generally smoother than the observed ones. For example, the valley value of SEC in 2012 was eliminated after subtracting the influence of the atmospheric circulation.

Table 7 presents the variation trends of $\overline{\mathrm{SEC}_{\mathrm{n}}}, \mathrm{E}_{\mathrm{n}}, \mathrm{O}_{\mathrm{n}}$ and $S_{n}$ during the periods of 2001-2005 and 2005-2015 in Chengdu and 2001-2009, 2009-2014 and 2014-2016 in Chongqing. The ratios of the trends of $\mathrm{E}_{n}, \mathrm{O}_{n}$ and $\mathrm{S}_{\mathrm{n}}$ to those of $\overline{\mathrm{SEC}_{\mathrm{n}}}$ are also listed to show the contributions of these signals to the trends of SEC. In Chengdu, SEC increased (decreased) during 2001-2005 (2005-2015) with a trend of $2.745(-0.188) \mathrm{km}^{-1}$ per decade. During the growth period, introducing the intensity of circulation counteracted the effect of occurrence frequency. Only $0.15 \%$ of the SEC

Table 5. The SEC-PC regression expressions and corresponding correlation coefficients between the relative anomalies of SEC and PCs for each CT in Chengdu and Chongqing.

\begin{tabular}{|c|c|c|c|c|}
\hline \multirow{2}{*}{ CT } & \multicolumn{2}{|c|}{ Chengdu } & \multicolumn{2}{|c|}{ Chongqing } \\
\hline & regression & $\mathrm{R}$ & regression & $\mathrm{R}$ \\
\hline \multirow[t]{4}{*}{ CT1 } & $0.653 \times \mathrm{PC} 1+0.029$ & 0.83 & $-0.200 \times \mathrm{PC} 1+0.002$ & -0.73 \\
\hline & $0.221 \times \mathrm{PC} 2-0.020$ & 0.60 & $-0.468 \times \mathrm{PC} 2-0.032$ & -0.81 \\
\hline & $-0.040 \times$ PC3 -0.029 & -0.12 & $-0.215 \times$ PC3 -0.047 & -0.58 \\
\hline & $0.139 \times \mathrm{PC} 4-0.022$ & 0.28 & $-0.171 \times \mathrm{PC} 4-0.008$ & 0.82 \\
\hline \multirow[t]{4}{*}{$\mathrm{CT} 2$} & -0.028 & - & $-0.475 \times \mathrm{PC} 1+0.019$ & -0.82 \\
\hline & $-0.375 \times \mathrm{PC} 2+0.023$ & -0.55 & $-0.359 \times \mathrm{PC} 2-0.021$ & -0.76 \\
\hline & $0.463 \times \mathrm{PC} 3+0.021$ & 0.95 & $-0.506 \times \mathrm{PC} 3+0.019$ & -0.90 \\
\hline & $-0.256 \times \mathrm{PC} 4-0.007$ & -0.45 & $-0.117 \times \mathrm{PC} 4-0.014$ & -0.42 \\
\hline \multirow[t]{4}{*}{ CT3 } & $-0.053 \times \mathrm{PC} 1+0.022$ & -0.12 & $-0.743 \times \mathrm{PC} 1-0.015$ & -0.89 \\
\hline & $0.019 \times \mathrm{PC} 2+0.002$ & 0.04 & $0.157 \times \mathrm{PC} 2-0.019$ & 0.27 \\
\hline & $-0.049 \times \mathrm{PC} 3-0.010$ & -0.11 & $-0.234 \times \mathrm{PC} 3-0.029$ & -0.49 \\
\hline & $0.316 \times \mathrm{PC} 4-0.029$ & 0.46 & $-0.383 \times \mathrm{PC} 4+0.002$ & -0.85 \\
\hline \multirow[t]{4}{*}{ CT4 } & $-0.268 \times \mathrm{PC} 1+0.026$ & -0.73 & $-0.003 \times \mathrm{PC} 1-0.025$ & -0.01 \\
\hline & $-0.312 \times \mathrm{PC} 2-0.015$ & -0.69 & $0.310 \times \mathrm{PC} 2-0.010$ & 0.68 \\
\hline & $0.361 \times \mathrm{PC} 3+0.012$ & 0.84 & $0.684 \times \mathrm{PC} 3+0.052$ & 0.91 \\
\hline & $0.151 \times \mathrm{PC} 4+0.035$ & 0.46 & $-0.295 \times$ PC4 -0.009 & -0.61 \\
\hline
\end{tabular}

Note: The bold numbers in black and gray indicate the correlations are significant at level of 0.01 and 0.05 , respectively. 


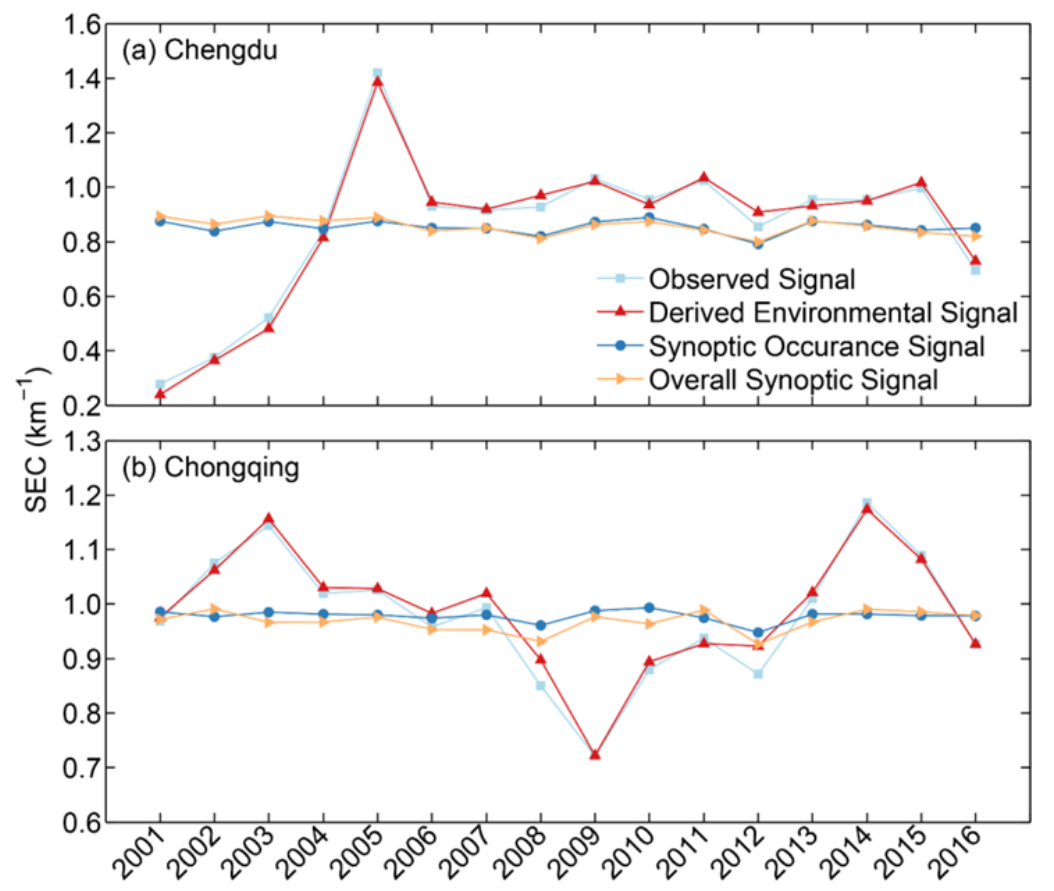

Fig. 11. The interannual variations of $\overline{\mathrm{SEC}_{n}}, E_{n}, \mathrm{O}_{n}$ and $\mathrm{S}_{\mathrm{n}}$ in Chengdu and Chongqing.

Table 6. The interannual variations of $\overline{\mathrm{SEC}_{n}}, \mathrm{O}_{\mathrm{n}}$ and $\mathrm{S}_{\mathrm{n}}$ in unit of $\mathrm{km}^{-1}$, and the ratios of the variations of $\mathrm{S}_{\mathrm{n}}$ to those of $\overline{\mathrm{SEC}_{\mathrm{n}}}$ in Chengdu and Chongqing.

\begin{tabular}{|c|c|c|c|c|c|c|c|c|}
\hline \multirow[b]{2}{*}{ year } & \multicolumn{4}{|c|}{ Chengdu } & \multicolumn{4}{|c|}{ Chongqing } \\
\hline & $\Delta \overline{\mathrm{SEC}_{\mathrm{n}}}\left(\mathrm{km}^{-1}\right)$ & $\Delta \mathrm{O}_{\mathrm{n}}\left(\mathrm{km}^{-1}\right)$ & $\Delta \mathrm{S}_{\mathrm{n}}\left(\mathrm{km}^{-1}\right)$ & $\frac{\Delta \mathrm{S}_{\mathrm{n}}}{\Delta \overline{\mathrm{SEC} C_{n}}}(\%)$ & $\Delta \overline{\mathrm{SEC}_{\mathrm{n}}}\left(\mathrm{km}^{-1}\right)$ & $\Delta \mathrm{O}_{\mathrm{n}}\left(\mathrm{km}^{-1}\right)$ & $\Delta \mathrm{S}_{\mathrm{n}}\left(\mathrm{km}^{-1}\right)$ & $\frac{\Delta \mathrm{S}_{\mathrm{n}}}{\Delta \mathrm{SEC}_{\mathrm{n}}}(\%)$ \\
\hline $2002-2001$ & 0.098 & -0.037 & -0.028 & -28.82 & 0.106 & -0.009 & 0.019 & 18.09 \\
\hline 2003-2002 & 0.147 & 0.036 & 0.031 & 20.81 & 0.069 & 0.009 & -0.025 & -35.42 \\
\hline 2004-2003 & 0.314 & -0.025 & -0.019 & -5.95 & -0.125 & -0.004 & 0.001 & -0.53 \\
\hline 2005-2004 & 0.583 & 0.027 & 0.013 & 2.17 & 0.006 & -0.001 & 0.009 & 140.74 \\
\hline 2006-2005 & -0.488 & -0.026 & -0.050 & 10.20 & -0.068 & -0.006 & -0.023 & 34.03 \\
\hline 2007-2006 & -0.015 & -0.001 & 0.011 & -74.35 & 0.035 & 0.006 & -0.001 & -2.20 \\
\hline 2008-2007 & 0.012 & -0.030 & -0.038 & -315.67 & -0.143 & -0.019 & -0.021 & 14.89 \\
\hline 2009-2008 & 0.102 & 0.052 & 0.051 & 50.19 & -0.130 & 0.027 & 0.045 & -35.12 \\
\hline 2010-2009 & -0.076 & 0.017 & 0.010 & -13.51 & 0.159 & 0.005 & -0.013 & -8.02 \\
\hline 2011-2010 & 0.069 & -0.043 & -0.031 & -44.79 & 0.058 & -0.018 & 0.025 & 43.63 \\
\hline 2012-2011 & -0.169 & -0.054 & -0.043 & 25.52 & -0.066 & -0.027 & -0.062 & 94.44 \\
\hline 2013-2012 & 0.100 & 0.084 & 0.077 & 76.82 & 0.138 & 0.034 & 0.040 & 29.07 \\
\hline 2014-2013 & -0.001 & -0.014 & -0.019 & 1716.48 & 0.176 & 0.000 & 0.024 & 13.44 \\
\hline 2015-2014 & 0.043 & -0.020 & -0.024 & -55.18 & -0.097 & -0.003 & -0.005 & 5.45 \\
\hline 2016-2015 & -0.301 & 0.008 & -0.014 & 4.53 & -0.162 & -0.001 & -0.007 & 4.22 \\
\hline
\end{tabular}

Note: The shaded number means the overall synoptic signal varies in opposite direction to the observed signal in this year.

trend was attributed to atmospheric circulation, which elucidates that the strong increase was the result of nonsynoptic factors. During the slight decline period the contribution of atmospheric circulation accounted for $7.96 \%$ of the decreasing trend. SEC in Chongqing decreased, increased and then decreased again during 2001-2009, 2009-2014 and 2014-2016 with trends of $-0.338,0.758$ and $-1.297 \mathrm{~km}^{-1}$ per decade, respectively. Similar to Chengdu, the contributions of atmospheric circulation were relatively higher during the declining periods. During 2001-2009 and 2014-2016, about $10.00 \%$ and $4.68 \%$, respectively, of the increasing trends were caused by atmospheric circulation. By contrast, the contribution during 2009-2014 was 0.67\%.

\section{CONCLUSIONS}

In this study, the characteristics of atmospheric circulation in the Sichuan Basin during the winters of 2001-2016 were first analyzed by CTC. Then, based on the results, the effect of circulation patterns on the relationship between the SEC and meteorological parameters was 
Table 7. The variation trends of $\overline{\mathrm{SEC}_{n}}, \mathrm{E}_{n}, \mathrm{O}_{\mathrm{n}}$ and $\mathrm{S}_{\mathrm{n}}$ in unit of $\mathrm{km}^{-1}$ per decade, and the ratios of the trends of $\mathrm{E}_{\mathrm{n}}, \mathrm{O}_{\mathrm{n}}$ and $\mathrm{S}_{\mathrm{n}}$ to those of $\overline{\mathrm{SEC}_{\mathrm{n}}}$ during selected periods in Chengdu and Chongqing.

\begin{tabular}{llllll}
\hline \multirow{2}{*}{ Signal } & \multicolumn{2}{c}{ Chengdu $\left(\mathrm{km}^{-1}\right.$ per decade $)$} & \multicolumn{3}{c}{ Chongqing $\left(\mathrm{km}^{-1}\right.$ per decade $)$} \\
\cline { 2 - 6 } & $2001-2005$ & $2005-2015$ & $2001-2009$ & $2009-2014$ & $2014-2016$ \\
\hline$\overline{\mathrm{SEC}_{\mathrm{n}}}$ & 2.745 & -0.188 & -0.338 & 0.758 & -1.297 \\
$\mathrm{E}_{\mathrm{n}}$ & 2.741 & -0.173 & -0.305 & 0.753 & -1.236 \\
& $99.85 \%$ & $92.04 \%$ & $90.00 \%$ & $99.33 \%$ & $95.32 \%$ \\
$\mathrm{O}_{\mathrm{n}}$ & 0.012 & -0.011 & -0.010 & -0.026 & -0.018 \\
& $0.45 \%$ & $5.99 \%$ & $2.81 \%$ & $-3.39 \%$ & $1.39 \%$ \\
$\mathrm{~S}_{\mathrm{n}}$ & 0.004 & -0.015 & -0.034 & 0.005 & -0.061 \\
& $0.15 \%$ & $7.96 \%$ & $10.00 \%$ & $0.67 \%$ & $4.68 \%$ \\
\hline
\end{tabular}

investigated. In both Chengdu and Chongqing, a weak high-pressure system (CT 3) and a local low-pressure system (CT 4) were responsible for the highest and lowest SEC values, respectively, whereas the northerly centered high (CT 1)- and low (CT 2)-pressure systems were associated with medium-level air pollution. Synoptic dynamic factors, such as wind, subsidence, inversion and PBLH, dominated the variation in SEC between CTs. Furthermore, the influence of atmospheric circulation was stronger in Chengdu than Chongqing.

A new method for discriminating synoptic from nonsynoptic signals in the observed SEC series was developed to assess the contributions of synoptic signals to the interannual variations of the SEC. This method improved upon earlier studies, which used a single presumed parameter, by applying multiple influential meteorological parameters to assess the effect of atmospheric circulation intensity on the SEC. The interannual SEC variations in these cities were heightened by atmospheric circulation in more than half of the years but reduced by it in the remaining years. Additionally, circulation contributed 5$10 \%$ to the decreasing SEC trend but less than $1 \%$ to the increasing trend.

The selection of influential parameters is critical in this newly developed method and usually based on a priori knowledge. In addition to the four parameters (WS, RH, T and PBLH) considered in this work, factors such as wind direction, atmospheric inversion and vertical velocity may also significantly influence the SEC. Since these factors are directional or related to vertical profiles, they must be parameterized, which requires further research.

\section{ACKNOWLEDGMENTS}

This work was supported in parts by the National Key R\&D Program of China (grant numbers 2016YFC0200405 and 2018YFC0214002), the "Light of West China" Program of the Chinese Academy of Sciences, and National Natural Science Foundation of China (grant numbers 41875162 and 91544109).

\section{SUPPLEMENTARY MATERIAL}

Supplementary data associated with this article can be found in the online version at http://www.aaqr.org.

\section{REFERENCES}

Allwine, K.J. and Whiteman, C.D. (1994). Single-station integral measures of atmospheric stagnation, recirculation and ventilation. Atmos. Environ. 28: 713-721.

Chan, C.K. and Yao, X. (2008). Air pollution in mega cities in China. Atmos. Environ. 42: 1-42.

Che, H., Zhang, X.Y., Xia, X., Goloub, P., Holben, B., Zhao, H., Wang, Y., Zhang, X.C., Wang, H., Blarel, L., Damiri, B., Zhang, R., Deng, X., Ma, Y., Wang, T., Geng, F., Qi, B., Zhu, J., Yu, J., Chen, Q. and Shi, G. (2015). Ground-based aerosol climatology of China: Aerosol optical depths from the China Aerosol Remote Sensing Network (CARSNET) 2002-2013. Atmos. Chem. Phys. 15: 7619-7652.

Che, H.Z., Zhang, X.Y., Li, Y., Zhou, Z.J. and Qu, J.J. (2007). Horizontal visibility trends in China 1981-2005. Geophys. Res. Lett. 34: L24706.

Chen, Y. and Xie, S.D. (2012). Temporal and spatial visibility trends in the Sichuan Basin, China, 1973 to 2010. Atmos. Res. 112: 25-34.

Chen, Z.H., Cheng, S.Y., Li, J.B., Guo, X.R., Wang, W.H. and Chen, D.S. (2008). Relationship between atmospheric pollution processes and synoptic pressure patterns in northern China. Atmos. Environ. 42: 6078-6087.

Comrie, A.C. (1992). A procedure for removing the synoptic climate signal from environmental data. Int. $J$. Climatol. 12: 177-183.

Feng, X.Y., Liu, C.H., Fan, G.Z., Liu, X.D. and Feng, C.Y. (2016). Climatology and structures of southwest vortices in the NCEP climate forecast system reanalysis. J. Clim. 29: 7675-7701.

Feng, Y.R., Wang, A.Y., Wu, D. and Xu, X.D. (2007). The influence of tropical cyclone Melor on $\mathrm{PM}_{10}$ concentrations during an aerosol episode over the Pearl River Delta region of China: Numerical modeling versus observational analysis. Atmos. Environ. 41: 4349-4365.

He, X., Li, C.C., Lau, A.K.H., Deng, Z.Z., Mao, J.T., Wang, M.H. and Liu, X.Y. (2009). An intensive study of aerosol optical properties in Beijing urban area. Atmos. Chem. Phys. 9: 8903-8915.

Hegarty, J., Mao, H. and Talbot, R. (2007). Synoptic controls on summertime surface ozone in the northeastern United States. J. Geophys. Res. 112: D14306.

Hu, X.M., Zhang, Y., Jacobson, M.Z. and Chan, C.K. (2008). Coupling and evaluating gas/particle mass 
transfer treatments for aerosol simulation and forecast. J. Geophys. Res. 113: D11208.

Koschmieder, H. (1926). Theorie der horizontalen sichtweite. Beitsaege Phys. Atmos. 12: 33-55.

Li, J., Li, C.C., Zhao, C.S. and Su, T.N. (2016). Changes in surface aerosol extinction trends over China during 1980-2013 inferred from quality-controlled visibility data. Geophys. Res. Lett. 43: 8713-8719.

Li, L., Qian, J., Ou, C.Q., Zhou, Y.X., Guo, C. and Guo, Y.M. (2014). Spatial and temporal analysis of Air Pollution Index and its timescale-dependent relationship with meteorological factors in Guangzhou, China, 20012011. Environ. Pollut. 190: 75-81.

Lin, C., Li, Y., Yuan, Z., Lau, A.K., Li, C. and Fung, J.C. (2015). Using satellite remote sensing data to estimate the high-resolution distribution of ground-level $\mathrm{PM}_{2.5}$. Remote Sens Environ 156: 117-128.

Liu, X.G., Li, J., Qu, Y., Han, T., Hou, L., Gu, J., Chen, C., Yang, Y., Liu, X., Yang, T., Zhang, Y., Tian, H. and $\mathrm{Hu}$, M. (2013). Formation and evolution mechanism of regional haze: A case study in the megacity Beijing, China. Atmos. Chem. Phys. 13: 4501-4514.

Liu, X.Y., Chen, Q.L., Che, H.Z., Zhang, R.J., Gui, K., Zhang, H. and Zhao, T.L. (2016). Spatial distribution and temporal variation of aerosol optical depth in the Sichuan basin, China, the recent ten years. Atmos. Environ. 147: 434-445.

Meng, F., Cao, C.Y. and Shao, X. (2015). Spatio-temporal variability of Suomi-NPP VIIRS-derived aerosol optical thickness over China in 2013. Remote Sens. Environ. 163: 61-69.

Miao, Y.C., Liu, S.H., Zheng, Y.J., Wang, S. and Chen, B.C. (2015). Numerical study of the effects of topography and urbanization on the local atmospheric circulations over the Beijing-Tianjin-Hebei, China. $A d v$. Meteorol. 2015: 397070.

Murray, F.W. (1967). On the computation of saturation vapor pressure. J. Appl. Meteorol.: 203-204.

Pateraki, S., Asimakopoulos, D.N., Flocas, H.A., Maggos, T. and Vasilakos, C. (2012). The role of meteorology on different sized aerosol fractions $\left(\mathrm{PM}_{10}, \mathrm{PM}_{2.5}, \mathrm{PM}_{2.5-10}\right)$. Sci. Total Environ. 419: 124-135.

Pearce, J.L., Beringer, J., Nicholls, N., Hyndman, R.J. and Tapper, N.J. (2011a). Quantifying the influence of local meteorology on air quality using generalized additive models. Atmos. Environ. 45: 1328-1336.

Pearce, J.L., Beringer, J., Nicholls, N., Hyndman, R.J., Uotila, P. and Tapper, N.J. (2011b). Investigating the influence of synoptic-scale meteorology on air quality using self-organizing maps and generalized additive modelling. Atmos. Environ. 45: 128-136.

Petaja, T., Jarvi, L., Kerminen, V.M., Ding, A.J., Sun, J.N., Nie, W., Kujansuu, J., Virkkula, A., Yang, X.Q., Fu, C.B., Zilitinkevich, S. and Kulmala, M. (2016). Enhanced air pollution via aerosol-boundary layer feedback in China. Sci. Rep. 6: 18998.

Philipp, A., Bartholy, J., Beck, C., Erpicum, M., Esteban, P., Fettweis, X., Huth, R., James, P., Jourdain, S., Kreienkamp, F., Krennert, T., Lykoudis, S., Michalides,
S.C., Pianko-Kluczynska, K., Post, P., Alvarez, D.R., Schiemann, R., Spekat, A. and Tymvios, F.S. (2010). Cost733cat - A database of weather and circulation type classifications. Phys. Chem. Earth 35: 360-373.

Philipp, A., Beck, C., Huth, R. and Jacobeit, J. (2016). Development and comparison of circulation type classifications using the COST 733 dataset and software. Int. J. Climatol. 36: 2673-2691.

Pitchford, M., Malm, W., Schichtel, B., Kumar, N., Lowenthal, D. and Hand, J. (2007). Revised algorithm for estimating light extinction from IMPROVE particle speciation data. J. Air Waste Manage. Assoc. 57: 13261336.

Seinfeld, J.H. and Pandis, S.N. (2016). Atmospheric chemistry and physics: From air pollution to climate change. John Wiley \& Sons, New York.

Sun, Y.L., Wang, Z.F., Fu, P.Q., Jiang, Q., Yang, T., Li, J. and Ge, X.L. (2013). The impact of relative humidity on aerosol composition and evolution processes during wintertime in Beijing, China. Atmos. Environ. 77: 927934.

Tai, A.P.K., Mickley, L.J. and Jacob, D.J. (2010). Correlations between fine particulate matter $\left(\mathrm{PM}_{2.5}\right)$ and meteorological variables in the United States: Implications for the sensitivity of $\mathrm{PM}_{2.5}$ to climate change. Atmos. Environ. 44: 3976-3984.

Tao, J., Zhang, L.M., Cao, J.J. and Zhang, R.J. (2017). A review of current knowledge concerning $\mathrm{PM}_{2.5}$ chemical composition, aerosol optical properties and their relationships across China. Atmos. Chem. Phys. 17: 9485-9518.

Wang, H., Tian, M., Chen, Y., Shi, G., Chemistry, X.C.J.A. and Physics (2018). Seasonal characteristics, formation mechanisms and source origins of $\mathrm{PM}_{2.5}$ in two megacities in Sichuan Basin, China. Atmos. Chem. Phys. 18: 865-881.

Wang, H.B., Yang, F.M., Shi, G.M., Tian, M., Zhang, L.M., Zhang, L.Y. and Fu, C.A. (2016). Ambient concentration and dry deposition of major inorganic nitrogen species at two urban sites in Sichuan Basin, China. Environ. Pollut. 219: 235-244.

Wang, H.B., Shi, G.M., Tian, M., Zhang, L.M., Chen, Y., Yang, F.M. and Cao, X.Y. (2017). Aerosol optical properties and chemical composition apportionment in Sichuan Basin, China. Sci. Total Environ. 577: 245-257.

Wang, Q.W. and Tan, Z.M. (2014). Multi-scale topographic control of southwest vortex formation in Tibetan Plateau region in an idealized simulation. J. Geophys. Res. 119: 11543-11561.

Wang, S.L., Chai, F.H. and Zhang, Y.H. (2004). Analysis on the sources and characters of particles in Chengdu. Sci. Geog. Sinica 24: 488-492.

Wang, Y.G., Ying, Q., Hu, J.L. and Zhang, H.L. (2014). Spatial and temporal variations of six criteria air pollutants in 31 provincial capital cities in China during 2013-2014. Environ. Int. 73: 413-422.

Wei, P., Cheng, S.Y., Li, J.B. and Su, F.Q. (2011). Impact of boundary-layer anticyclonic weather system on regional air quality. Atmos. Environ. 45: 2453-2463. 
Wu, J., Fu, C.B., Zhang, L.Y. and Tang, J.P. (2012). Trends of visibility on sunny days in china in the recent 50 years. Atmos. Environ. 55: 339-346.

Wu, M., Wu, D., Fan, Q., Wang, B.M., Li, H.W. and Fan, S.J. (2013). Observational studies of the meteorological characteristics associated with poor air quality over the Pearl River Delta in China. Atmos. Chem. Phys. 13: 10755-10766.

Yan, J.P., Chen, L.Q., Lin, Q., Zhao, S.H. and Zhang, M.M. (2016). Effect of typhoon on atmospheric aerosol particle pollutants accumulation over Xiamen, China. Chemosphere 159: 244-255.

Yang, F., Tan, J., Zhao, Q., Du, Z., He, K., Ma, Y., Duan, F., Chen, G., Zhao, Q.J.A.C. and Physics (2011). Characteristics of $\mathrm{PM}_{2.5}$ speciation in representative megacities and across China. Atmos. Chem. Phys. 11: 1025-1051.

Ye, D. and Gao, Y.X. (1979). The meteorology of the Qinghai-Xizang (Tibet) Plateau. Science Press, Beijing.

Ye, X.X., Song, Y., Cai, X.H. and Zhang, H.S. (2016). Study on the synoptic flow patterns and boundary layer process of the severe haze events over the North China Plain in January 2013. Atmos. Environ. 124: 129-145.

Zhang, H.L., Wang, Y.G., Hu, J.L., Ying, Q. and Hu, X.M. (2015a). Relationships between meteorological parameters and criteria air pollutants in three megacities in China. Environ. Res. 140: 242-254.

Zhang, J.P., Zhu, T., Zhang, Q.H., Li, C.C., Shu, H.L., Ying, Y., Dai, Z.P., Wang, X., Liu, X.Y., Liang, A.M., Shen, H.X. and Yi, B.Q. (2012). The impact of circulation patterns on regional transport pathways and air quality over Beijing and its surroundings. Atmos. Chem. Phys. 12: 5031-5053.
Zhang, L.M., Gong, S.L., Padro, J. and Barrie, L. (2001). A size-segregated particle dry deposition scheme for an atmospheric aerosol module. Atmos. Environ. 35: 549560.

Zhang, R.Y., Wang, G.H., Guo, S., Zarnora, M.L., Ying, Q., Lin, Y., Wang, W.G., Hu, M. and Wang, Y. (2015b). Formation of urban fine particulate matter. Chem. Rev. 115: 3803-3855.

Zhang, Y., Mao, H.T., Ding, A.J., Zhou, D.R. and Fu, C.B. (2013). Impact of synoptic weather patterns on spatiotemporal variation in surface $\mathrm{O}_{3}$ levels in Hong Kong during 1999-2011. Atmos. Environ. 73: 41-50.

Zhao, S., Li, J.P. and Sun, C. (2016a). Decadal variability in the occurrence of wintertime haze in central eastern China tied to the Pacific Decadal Oscillation. Sci. Rep. 6: 27424.

Zhao, S.P., Yu, Y., Yin, D.Y., He, J.J., Liu, N., Qu, J.J. and Xiao, J.H. (2016b). Annual and diurnal variations of gaseous and particulate pollutants in 31 provincial capital cities based on in situ air quality monitoring data from China National Environmental Monitoring Center. Environ. Int. 86: 92-106.

Zheng, X.Y., Fu, Y.F., Yang, Y.J. and Liu, G.S. (2015). Impact of atmospheric circulations on aerosol distributions in autumn over eastern China: Observational evidence. Atmos. Chem. Phys. 15: 12115-12138.

Received for review, September 12, 2018

Revised, January 28, 2019 Accepted, February 4, 2019 